\title{
La circulación interregional en el valle Calchaquí (Provincia de Salta, Noroeste argentino): una vi- sión integral desde nuevas y viejas evidencias
}

\author{
Marina SPROVIERI \\ CONICET - Museo de La Plata (Universidad Nacional de La Plata) \\ msprovieri@fcnym.unlp.edu.ar
}

Recibido: 17 de julio de 2013

Aceptado: 7 de octubre de 2014

\begin{abstract}
RESUMEN
Este trabajo presenta los resultados del estudio sistemático de la circulación de bienes, recursos e ideas en el valle Calchaquí (Provincia de Salta, Noroeste argentino) entre los siglos X y XVI. A través del análisis estilístico y de procedencia de colecciones arqueológicas de museos se plantea la diversidad de materiales e información que se movilizaron hacia y desde el valle en distintos momentos de su historia de ocupación. Estos nuevos datos se consideran en relación con la información existente sobre vinculaciones interregionales para las sociedades calchaquíes y se plantea la existencia de múltiples posibles circuitos que las conectarían con otros ámbitos culturales y ecológicos; circuitos que mostrarían modificaciones a partir de la ocupación inkaica del valle Calchaquí.
\end{abstract}

Palabras clave: Valle Calchaquí, circulación interregional, análisis estilísticos, determinación de fuentes de procedencia, siglos X a XVI.

\section{Interregional Circulation in the Calchaqui Valley (Province of Salta, Northwestern Argentina): A Comprehensive View from New and Old Evidence}

\begin{abstract}
This work presents the results of the systematic study concerning the circulation of goods, raw materials and ideas in the Calchaquí Valley (Province of Salta, Northwestern Argentina) between the $10^{\text {th }}$ and $16^{\text {th }}$ centuries. Through stylistic and provenance analyses of various materials from museums' archaeological collections, it was possible to establish the diversity of goods and materials that circulated to and from the valley in different moments of its occupational history. These new findings were considered in relation to already existing information about interregional connections for the Calchaquí societies, and the existence of several potential interaction circuits with different ecological and cultural areas was postulated. Such circuits apparently show certain changes since the Inka arrival to the Calchaquí Valley.
\end{abstract}

Key words: Calchaquí Valley, interregional circulation, stylistic analysis, provenance analysis, $10^{\text {th }}$ to $16^{\text {th }}$ centuries.

Sumario: 1. Introducción. 2. Materiales arqueológicos estudiados. 3. Evidencias de circulación interregional desde análisis estilísticos y de procedencia. 4. Sobre contextos y cronología. 5. Circulación interregional tardía en el valle Calchaquí. 6. Referencias bibliográficas.

\section{Introducción}

El valle Calchaquí, en el centro-oeste de la Provincia de Salta, Noroeste argentino (NOA), se ubica en un área geográfica intermedia entre las regiones puneñas occidentales y las zonas más bajas, húmedas y boscosas del oriente (Figura 1). Su disposición longitudinal, su dirección norte-sur y su extensión de $200 \mathrm{~km}$ de largo lo convierten en una vía natural privilegiada de acceso y comunicación interregional del NOA (Ardissone 1940; Tarragó 1970). Aunque esta condición se destacó desde principios de 


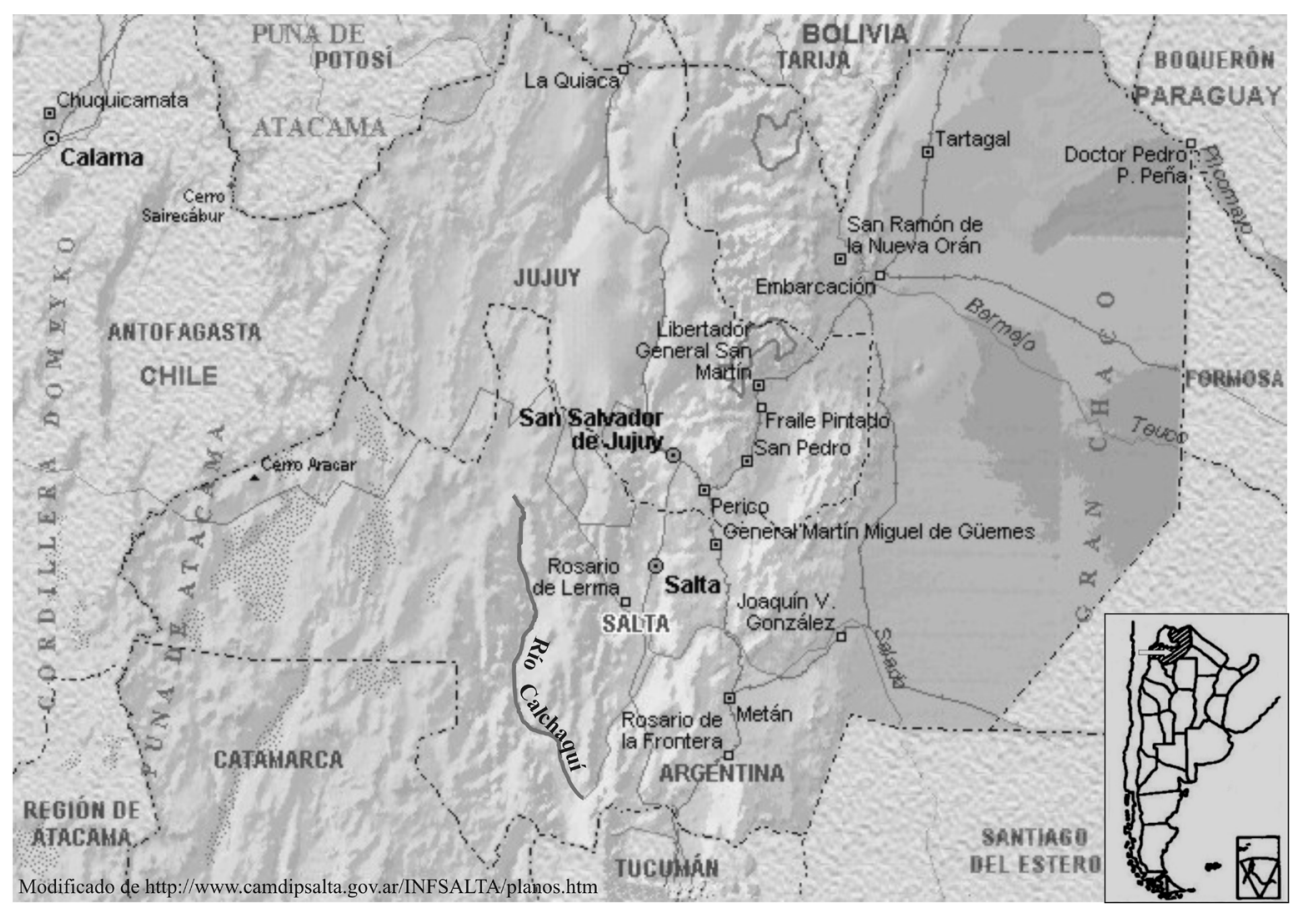

Figura 1: Mapa físico de la Provincia de Salta y de áreas aledañas del NOA, Chile y Bolivia, con la localización del valle Calchaquí.

siglo XX junto con la permanente mención de evidencias de circulación de bienes y recursos, hasta el momento no se había encarado un estudio sistemático de la circulación interregional en el valle Calchaquí.

En estas páginas se presenta un análisis integral de las múltiples líneas de evidencia que permiten profundizar en el conocimiento de las prácticas de circulación en las sociedades calchaquíes durante los Períodos de Desarrollos Regionales (900-1430/70 d.C.) e Inka (1430/70-1536 d.C.). A partir de la determinación de la variabilidad de bienes, recursos e información que se movilizaron hacia y desde la región, se proponen esferas de interacción y circuitos potenciales que vincularían el valle Calchaquí con diversas regiones (Sprovieri 2006, 2007, 2008a y b, 2010a).

\section{Materiales arqueológicos estudiados}

Ciertas colecciones arqueológicas constituyen un punto de partida importante para distinguir la variabilidad de bienes y materias primas utilizadas e intercambiadas en contextos y momentos específicos. Es el caso de la colección del sitio La Paya (Figura 2), cuyas dimensiones la hacen un referente del conjunto de materiales usados por las sociedades tardías ${ }^{1}$ del valle Calchaquí. Fue obtenida a principios del siglo XX median-

\footnotetext{
1 Se utiliza el término «tardía/o» para referirse al lapso correspondiente a los últimos siglos prehispánicos, específicamente los Períodos de Desarrollos Regionales e Inka.
} 
Figura 2: Mapa del valle Calchaquí con la ubicación de localidades y sitios tratados (modificado de Valencia et al. 1970: 1) Potrero de Payogasta, 2) Tero, 3) Choque, 4) Loma del Oratorio, 5) La Paya y Guitián, 6) El Churcal, 7) Tastil.

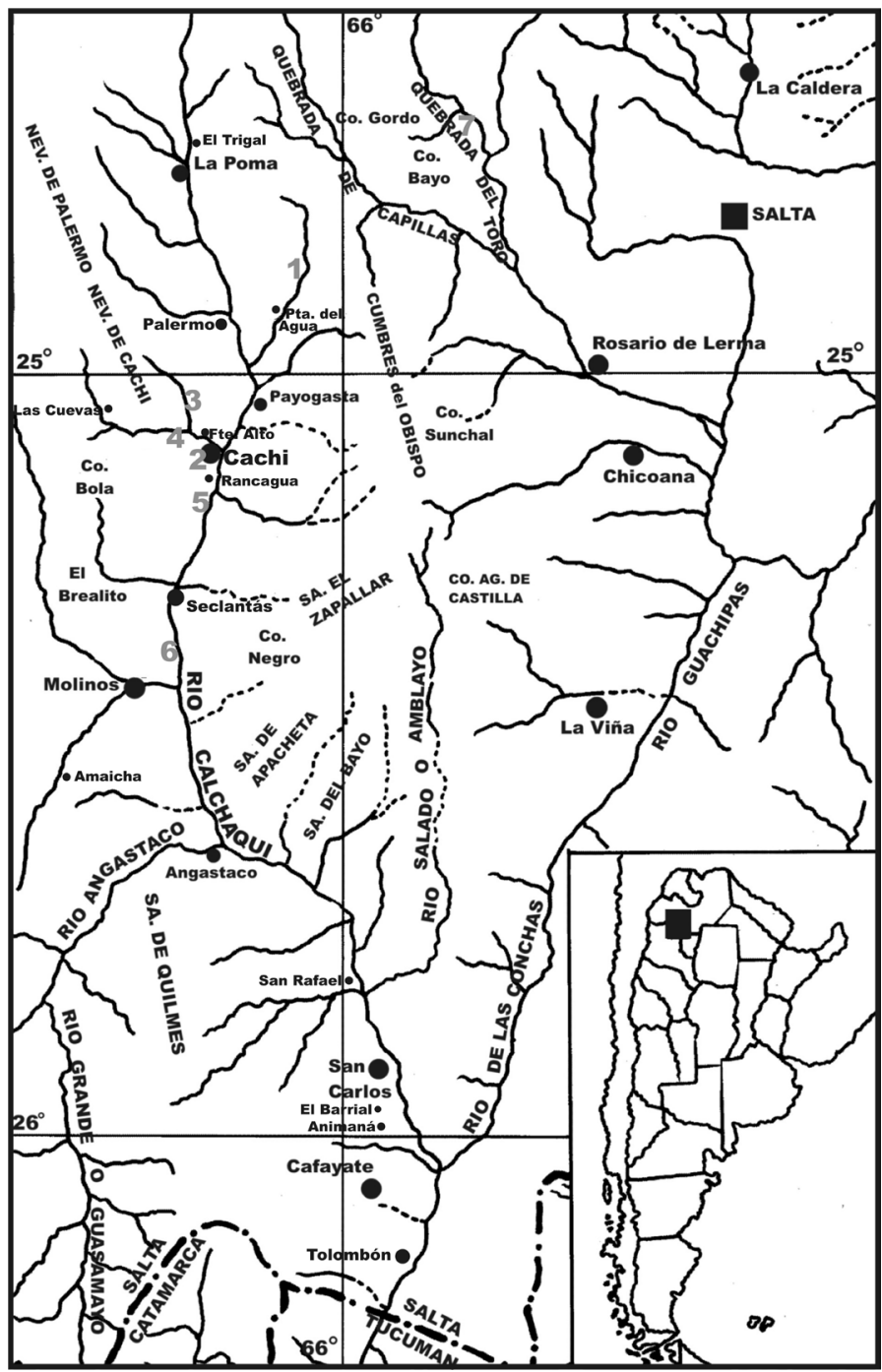

te la compra a pobladores locales (Ambrosetti 1902; Boman 1908) y la excavación de 203 contextos fundamentalmente funerarios (Ambrosetti 1907), y está compuesta de numerosas piezas completas o semi-completas de diversos tipos y materiales y cuenta con registros detallados de procedencia y asociaciones (Sprovieri 2010b).

El relevamiento de esta colección nos permitió analizar de manera directa 794 piezas, depositadas mayormente en el Museo Etnográfico «J. B. Ambrosetti» (ME) y en parte en otros museos del país y del extranjero ${ }^{2}$ (Sprovieri 2010b). Además, se analizaron otras 39 piezas procedentes del mismo sitio y depositadas en el Museo

2 En Argentina se estudiaron las piezas del Museo «E. Casanova» (Tilcara, Jujuy) y en los Estados Unidos las del American Museum of Natural History (Nueva York), el National Museum of the American Indian (Washington) y el National Museum of Natural History (Washington). 
Arqueológico «P. P. Díaz» de Cachi (MAC), obtenidas en rescates, exploraciones informales o donaciones.

Otra de las colecciones importantes del valle Calchaquí es la del sitio Tero (Figura 2), recuperada a fines de la década de 1970 en excavaciones de recintos y entierros (Tarragó et al. 1979) y actualmente depositada en el MAC, de la que se analizaron las 154 piezas más directamente relacionadas con el tema.

De manera más parcial se estudiaron otros conjuntos de materiales calchaquíes, como la colección de El Churcal (Figura 2), obtenida en la década de 1970 en excavaciones de estructuras funerarias y habitaciones (Raffino 1984), y las colecciones del Museo de La Plata (MLP) y del MAC, que reúnen materiales de distintas localidades del valle.

Cuadro 1: Número de piezas estudiadas según su procedencia

\begin{tabular}{|c|c|}
\hline Procedencia* & Total \\
\hline La Paya & 834 \\
\hline Tero & 154 \\
\hline Cachi & 14 \\
\hline La Poma & 6 \\
\hline El Churcal & 4 \\
\hline Fuerte Alto & 4 \\
\hline Loma del Oratorio & 3 \\
\hline Molinos & 1 \\
\hline Seclantás & 1 \\
\hline San Rafael & 1 \\
\hline Amaicha & 1 \\
\hline Guitián & 1 \\
\hline Choque & 1 \\
\hline Rancagua & 1 \\
\hline Río Las Cuevas & 1 \\
\hline TOTAL & 1027 \\
\hline
\end{tabular}

En total se analizaron 1027 piezas arqueológicas ${ }^{3}$ de diversos materiales que proceden de 15 sitios y localidades del valle Calchaquí, pero con el aporte mayoritario de las colecciones de los sitios La Paya y Tero (Cuadro 1). El análisis combinó acercamientos de aplicación factible en piezas de museo, sobre las cuales la intervención debía ser mínima. Por un lado, se utilizó una aproximación estilística que consideró rasgos formales, decorativos y tecnológicos en las piezas que, por comparación, pudieron asimilarse a determinados estilos y variedades ya descritos para el valle Calchaquí, el resto del NOA y los Andes Centro-sur, y que tienen valor cronológico relativo y determinada distribución espacial. Por otro lado, se emplearon técnicas físico-químicas y de las ciencias naturales para identificar la fuente de procedencia de determinados materiales.

\footnotetext{
3 En adelante para referirnos a piezas específicas se usará la sigla del museo al que pertenecen y su número de catálogo en el mismo (por ejemplo: $N^{\circ}$ MLP 001). Para las piezas de La Paya originalmente depositadas en el ME y luego canjeadas a otros museos se conserva la numeración del ME ya que es la que se corresponde con la presentada en la publicación de Ambrosetti (1907).
} 


\section{Evidencias de circulación interregional desde análisis estilísticos y de procedencia}

Los análisis desarrollados sobre la muestra permitieron reconocer distintos tipos de objetos y materiales que pueden ser considerados evidencias de circulación interregional. En cuanto a los análisis estilísticos, aplicados a toda la variabilidad de artefactos y materiales, las evidencias identificadas se presentan en dos conjuntos, uno correspondiente a los objetos cerámicos y otro correspondiente a los demás tipos de materiales.

Con respecto a la cerámica, se analizaron en total 463 piezas, en su mayoría vasijas enteras o parcialmente incompletas y también algunos fragmentos. Las piezas proceden principalmente de La Paya $(\mathrm{N}=338)$ y Tero $(\mathrm{N}=110)$, y en menor proporción de otras localidades del valle Calchaquí $(\mathrm{N}=15)$. Entre ellas se distinguen dos grandes grupos. Uno que incluye piezas que presentan características foráneas y otro que incluye piezas de rasgos locales pero que indican ciertos vínculos con otras regiones. El primer grupo se divide, a su vez, en piezas estilísticamente inkaicas, y que por lo tanto exhiben rasgos ajenos al acervo de las poblaciones locales, y en piezas no inkaicas.

Entre las vasijas estilísticamente inkaicas del primer grupo se diferencian diversas variantes estilísticas. Está presente la Inka Provincial (Raffino 1981; Calderari y Williams 1991) con distintas variedades: decorada, de superficie lisa pulida (negra o marrón/rojiza) y ordinaria, que suman 20 vasijas correspondientes mayormente a los denominados platos pato ${ }^{4}$, aribalos, jarritas de asa lateral y ollitas de pie de compotera (Figura 3).

Aparece también la Inka Mixto, en la que además de rasgos inkaicos se reconocen elementos provenientes de otras tradiciones estilísticas (Raffino 1981; Calderari y Williams 1991). Las más representadas son las piezas Casa Morada Polícromo $(\mathrm{N}=14)$, que incorporan elementos decorativos de la tradición Yavi, del sector NE de la puna de Jujuy y el sur de Bolivia (Tarragó 1974, 2000; Tarragó y De Lorenzi 1976; De Lorenzi y Díaz 1977) sobre formas inkaicas como platos pato, aribaloides, jarritas de asa lateral, y en escudillas (Figura 4). Las piezas provienen fundamentalmente de La Paya y algunas de Loma del Oratorio y del río Las Cuevas en Cachi Adentro (Figura 2).

Otro conjunto, de 4 piezas, muestra características de la tradición alfarera Yavi (Krapovickas y Aleksandrowicz 1986-87; Ávila 2006). Una de ellas es un aribaloide $\left(\mathrm{N}^{\circ}\right.$ ME 1737 en la Figura 5) con dos asas verticales asimétricas, decoración pintada en negro desleído de línea muy fina con los motivos que Ávila (2006: 59) denomina de «triángulo con espiral complejos» y una pasta en la que se observan las pequeñas inclusiones blancas características de la alfarería Yavi (Krapovickas y Aleksandrowicz 1986-87; Cremonte et al. 2007). Las demás vasijas son un aribaloide $\left(\mathrm{N}^{\circ} \mathrm{ME}\right.$ 3992 en la Figura 5) con decoración pintada en negro compuesta por una banda con una sucesión de triángulos espiralados, otra reticulada y la tercera por un zigzag de

4 Las designaciones de formas de vasijas en cursiva son aquellas que no surgen de la nomenclatura propuesta por Balfet et al. (1983), sino que son denominaciones comúnmente utilizadas en la arqueología del NOA. Se recurre a ellas para dar una idea más ajustada de la morfología de la/s pieza/s, dado que en el trabajo de Balfet et al. (1983) no queda contemplada una proporción importante de la variación y particularidades de la cerámica de esta región. 

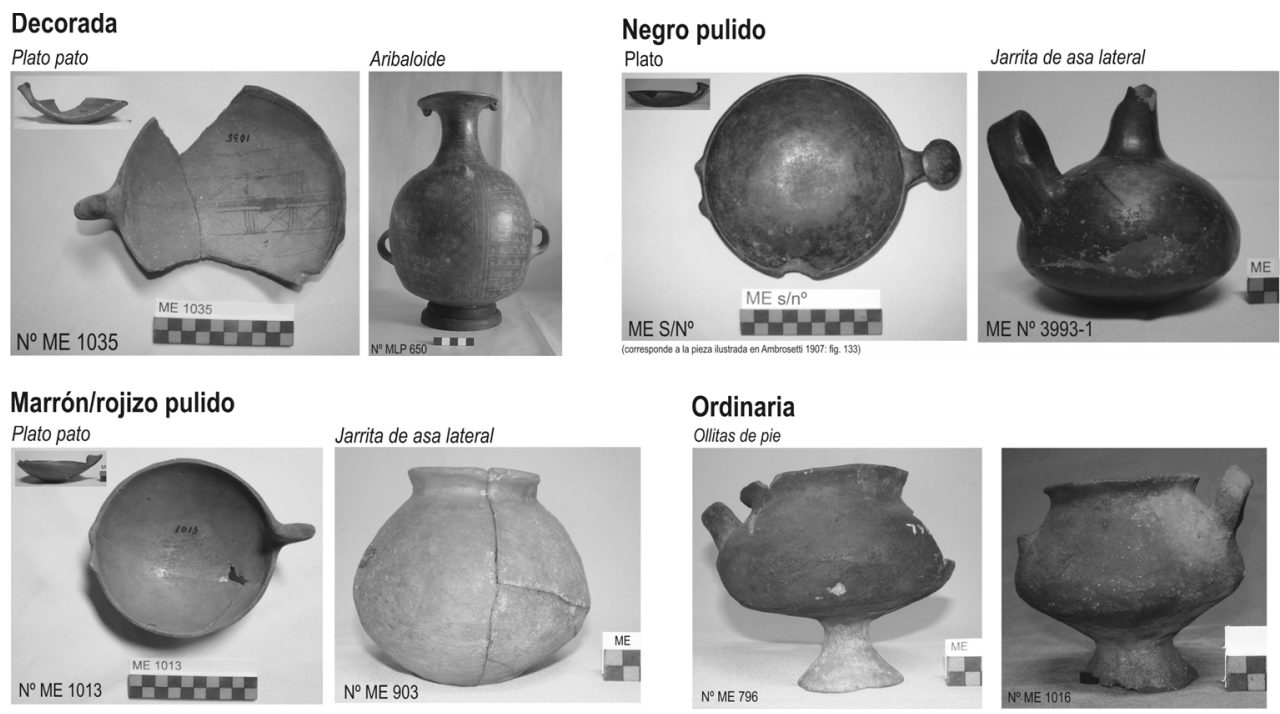

Figura 3: Variantes de la cerámica Inka Provincial en la muestra analizada.
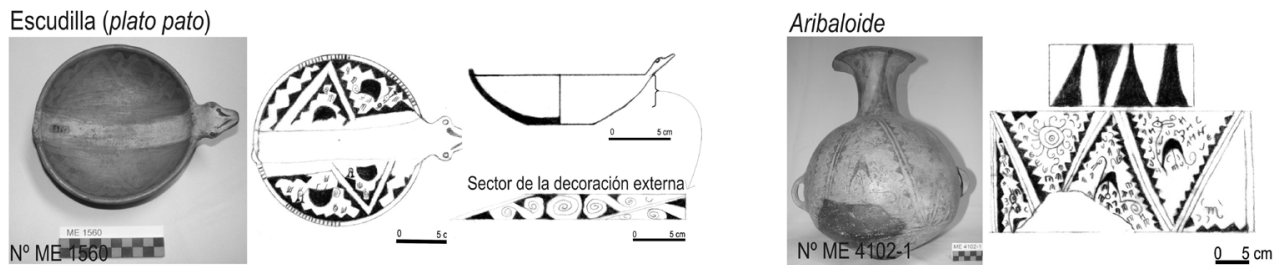

Figura 4: Cerámica Casa Morada Polícromo en la muestra analizada.

múltiples líneas. Finalmente, dos posibles escudillas, parcialmente remontadas, en las que se combina una estructura de diseño e iconografía inkaicas con motivos de espirales semejantes a los de la alfarería Yavi.

Por otro lado, se identificó un aribaloide de La Paya ( $\left.\mathrm{N}^{\circ} \mathrm{ME} 4102-2\right)$ que conjuga en su decoración elementos del Casa Morada Polícromo con una representación de peces similar a la de alfarería de la región altiplánica de Bolivia (zona de La Paz) que Portugal (1957: 389) identifica como suche (Trichomycterus rivulatus), un pez que habita en lagos y ríos altiplánicos sobre los $4.000 \mathrm{~m}$ de altura (Dyer 2000; Reis et al. 2003). En la vasija de La Paya la posición, cantidad y tamaño de aletas, los bigotes y el cuerpo alargado de la representación coinciden claramente con los de ese pez (Figura 6).

De La Paya también procede un fragmento de alfarería Pacajes del Altiplano boliviano (Rydén 1947; Munizaga 1957), con las clásicas «llamitas» pintadas en negro de este estilo. También se reconoció un aribaloide ( $\mathrm{N}^{\mathrm{o}}$ MAC 98), procedente de Choque (Figura 2), cuyo tratamiento de superficie, estructura de diseño e iconografía coincide estrechamente con los de la alfarería Diaguita Chilena, propia de la III y IV Región de Chile (Cornely 1947; Raffino 1981; Ampuero 1989) (Figura 7). Asimismo, 

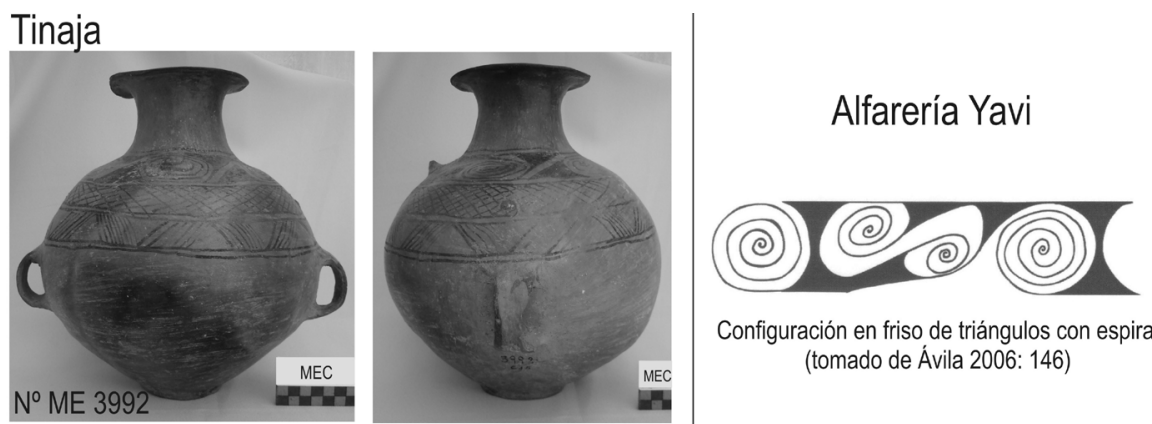

Configuración en friso de triángulos con espiral (tomado de Ávila 2006: 146)

\section{Aribaloide con asas asimétricas}
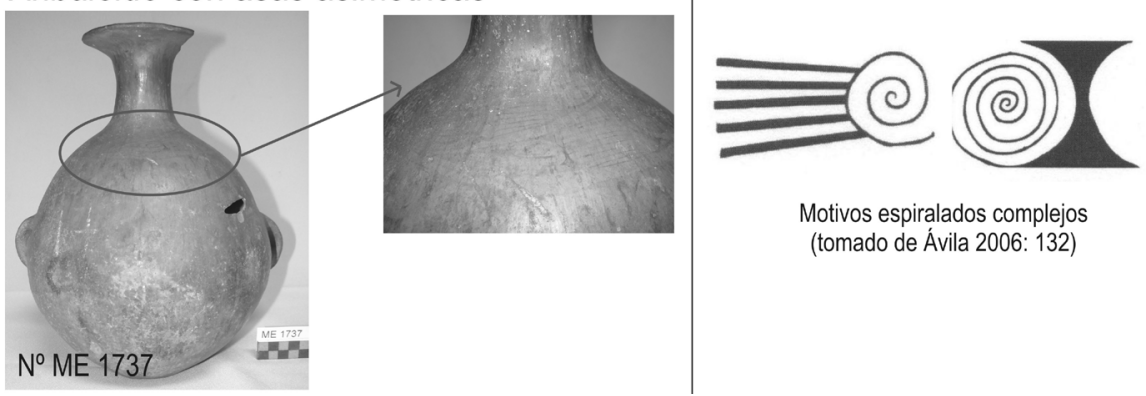

Motivos espiralados complejos

(tomado de Ávila 2006: 132)

Figura 5: Cerámica inka de rasgos similares a la tradición alfarera Yavi en la muestra analizada.
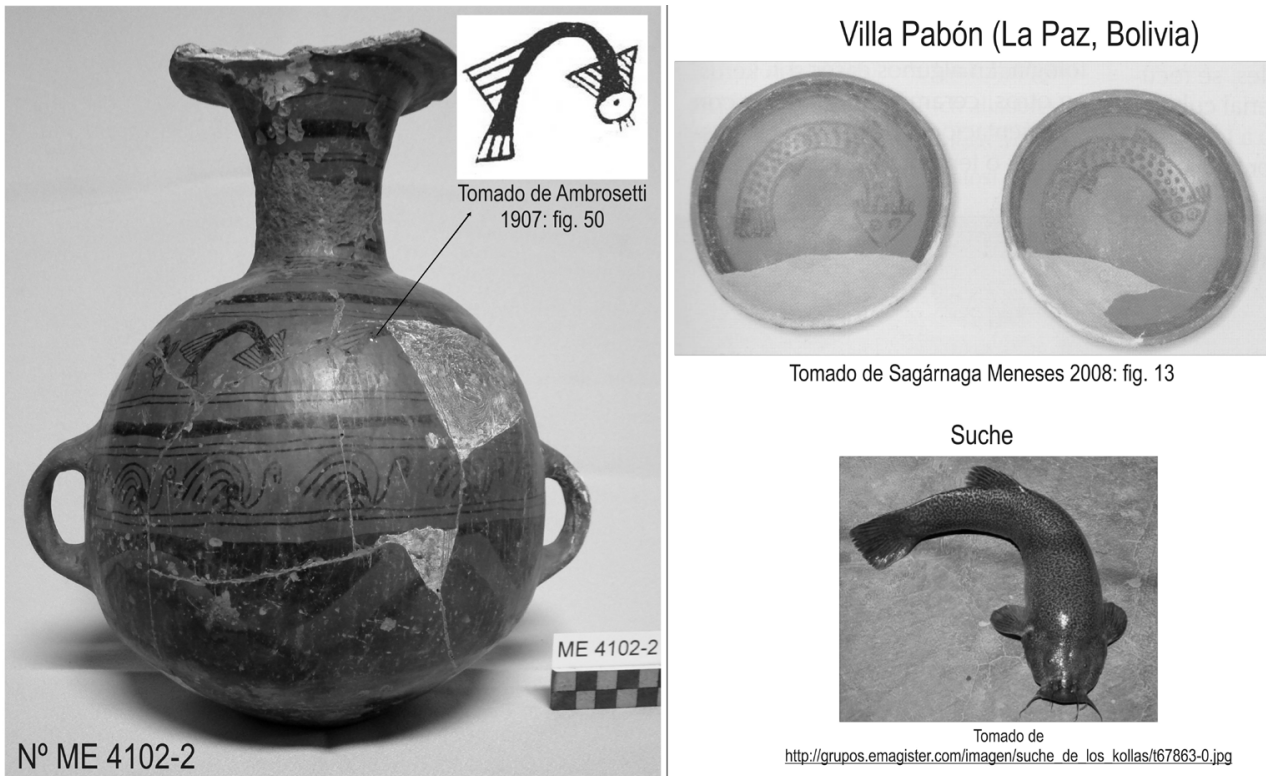

Tomado de Sagárnaga Meneses 2008: fig. 13

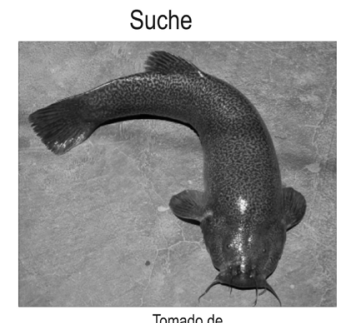

http://grupos.emagister.com/imagen/suche de los kollas/t67863-0.jpg

Figura 6: Vasija Inka Mixto con motivos ictiomorfos en la muestra analizada, iconografía similar en piezas de la zona de La Paz y pez al que correspondería. 

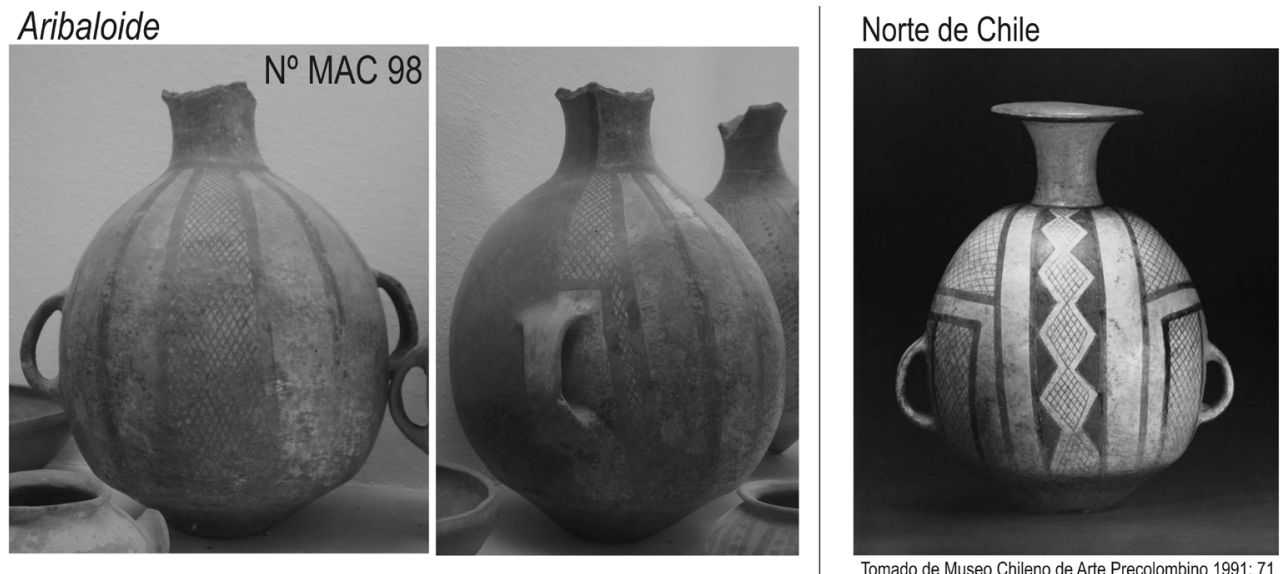

Figura 7: Vasija semejante a la alfarería Diaguita Chileno en la muestra analizada y similar del Norte de Chile.
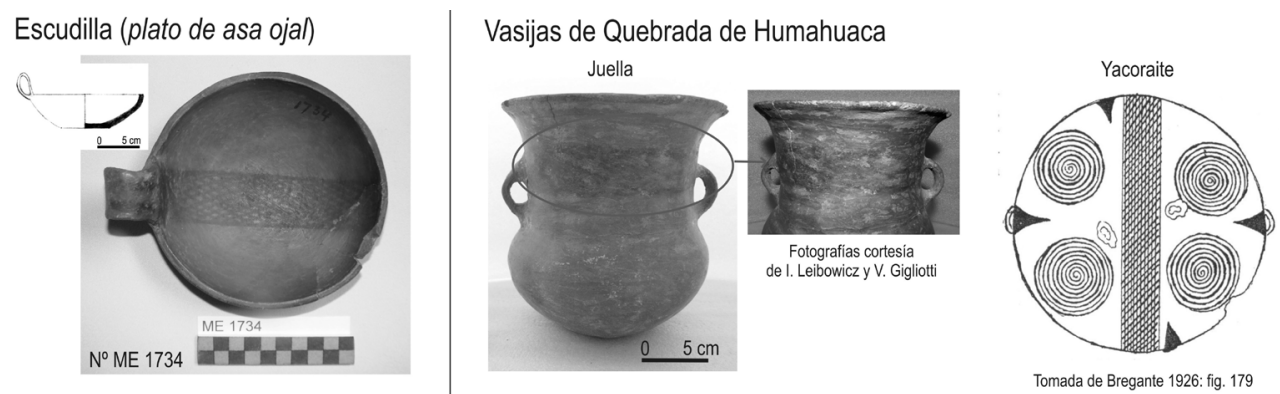

Figura 8: Plato inka en la muestra analizada y piezas similares de la Quebrada de Humahuaca.

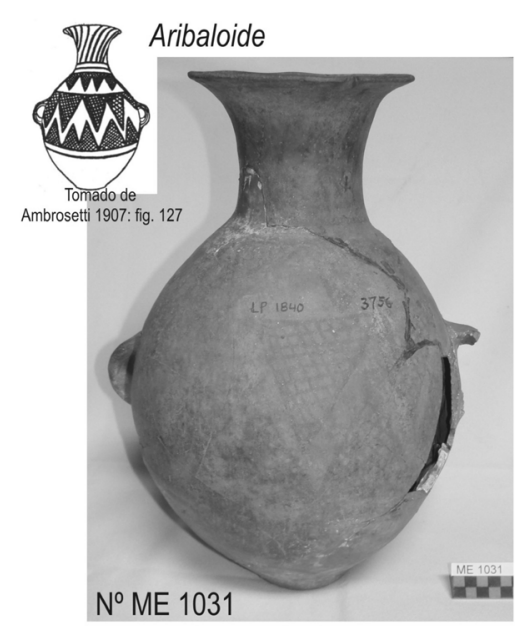

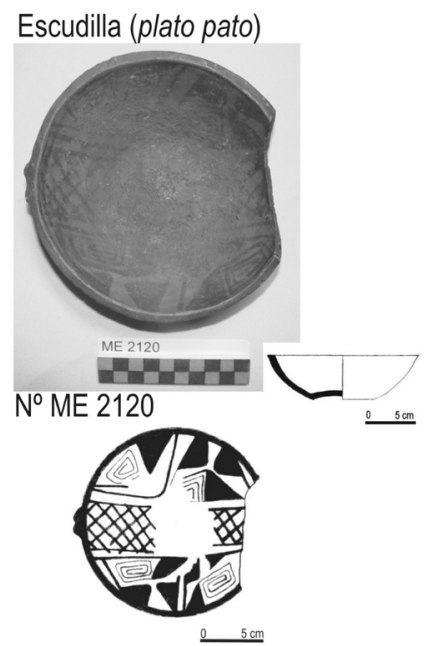

Figura 9: Cerámica La Paya Dibujos Negros en la muestra analizada. 

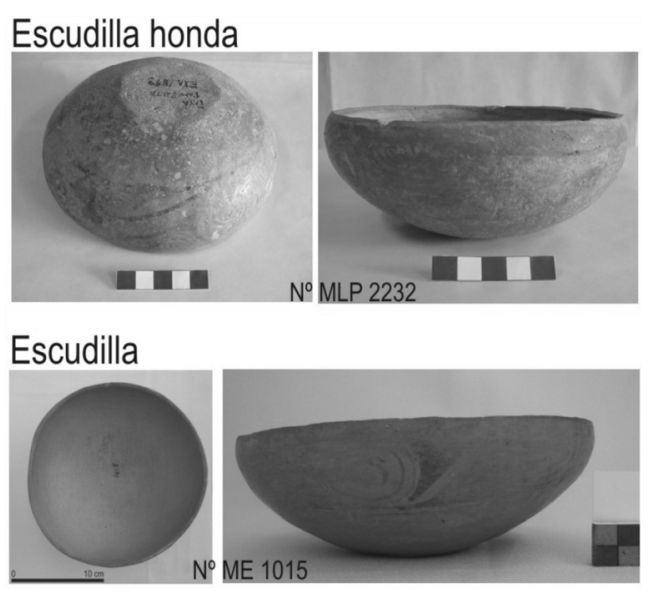

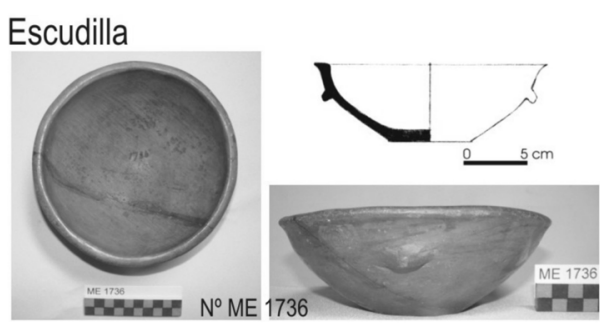

Escudilla

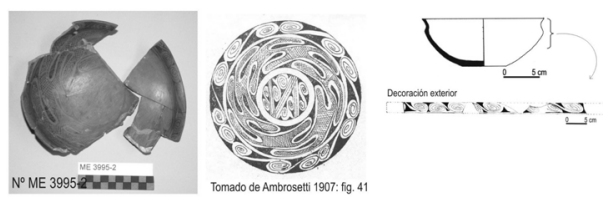

Figura 10: Piezas de similitud con la tradición alfarera Yavi en la muestra analizada.

se identificó una pieza de La Paya ( $\left.\mathrm{N}^{\circ} \mathrm{ME} 1734\right)$ que combina una morfología inkaica (plato de asa ojal) con decoración característica de la alfarería de la Quebrada de Humahuaca, en la Provincia de Jujuy, como lo es el reticulado de trazo fino cerrado aplicado en negro sobre un engobe rojo oscuro (Figura 8).

Por último, entre la cerámica Inka Mixto se incluyen 10 piezas de La Paya y Tero que corresponderían a la alfarería denominada La Paya Dibujos Negros (Serrano 1958; Calderari 1991a). Son tres aribaloides, dos escudillas y otras cinco vasijas pequeñas, de cuerpo en general globular con cuello y una o dos asas o un pico en la parte inferior del cuerpo, que por ciertas características de iconografía, acabado de superficie, colores y grosor del trazo pueden asemejarse a las piezas de ese estilo (Figura 9). Se ha planteado que en la decoración del La Paya Dibujos Negros es identificable cierta influencia de estilos de la Quebrada de Humahuaca, por ejemplo en la profusión de diseños reticulados (Calderari 1991a).

El otro conjunto dentro del grupo de piezas de rasgos foráneos es el correspondiente a las vasijas no inkaicas. En él se incluyen seis piezas de La Paya, cuyas formas y decoración se asemejan fuertemente a las de la tradición alfarera Yavi (Figura 10). Entre ellas se destacan una escudilla honda ( $\mathrm{N}^{\circ}$ MLP 2232), que corresponde a las que Ávila (2006: 40) denomina «escudillas hemisféricas simples», con decoración pintada en negro en una banda con motivos de «triángulos con espiral» (2006: 5859 ), y otra escudilla ( $\left.\mathrm{N}^{\circ} \mathrm{ME} 1015\right)$ que presenta una hendidura en el borde asemejándola a una media calabaza, forma señalada como «escudillas asimétricas del tipo calabaza» para el estilo Yavi (2006: 40-41). Un tipo diferente de escudilla es la pieza $\mathrm{N}^{\circ} \mathrm{ME} 1736$, la cual presenta un borde inflexionado, que se ha indicado como propio de las escudillas Yavi (2006: 39-40), y una decoración de líneas muy finas constituida por una banda de triángulos con espiral en el borde exterior y en el labio. Por último, es también destacable una escudilla de borde inflexionado decorada en negro de líneas muy finas ( $\mathrm{N}^{\circ}$ ME 3995-2). En sus bordes externo e interno la decoración está compuesta por una banda de triángulos con espiral, mientras que la superficie interna 

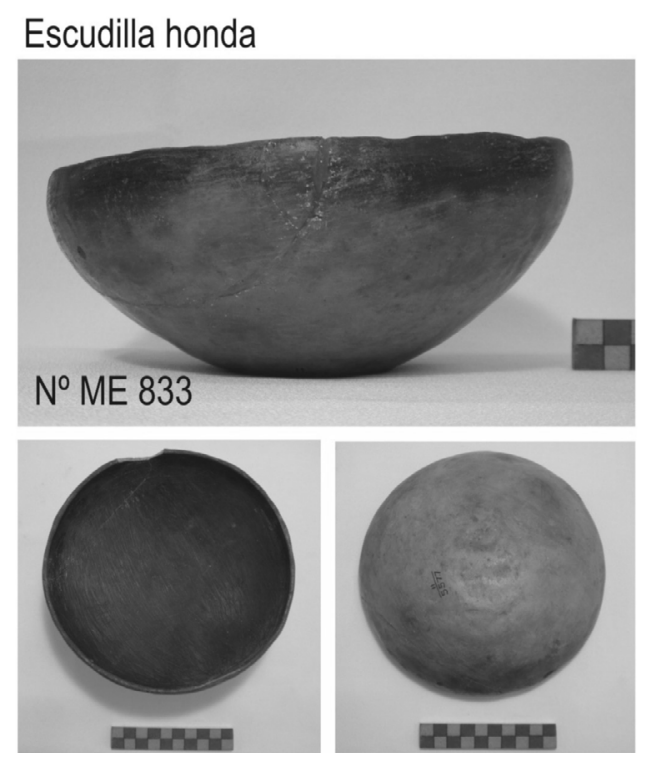

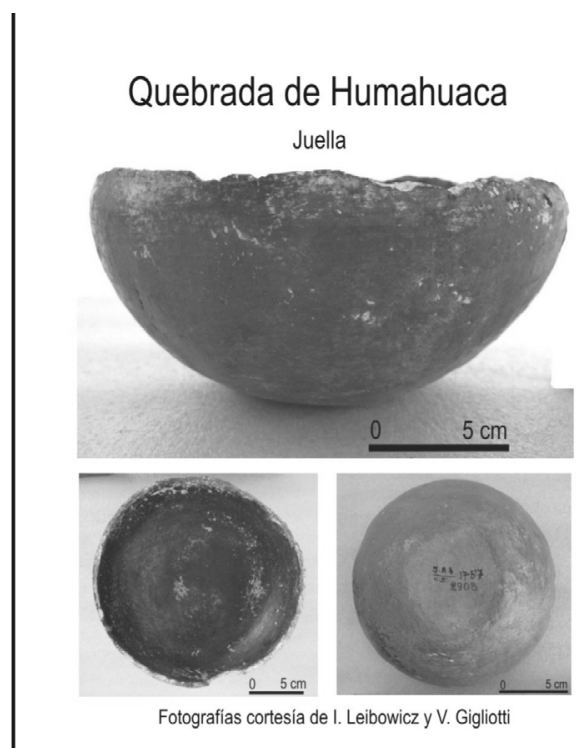

Figura 11: Pieza de interior negro pulido en la muestra analizada y similar de la Quebrada de Humahuaca.

restante por una «configuración radial» de «banda curva con reticulado fino cerrado» ${ }^{5}$ (2006: 57 y 67) en el cuerpo y por campos delimitados por un zigzag que contienen triángulos con espiral en la base.

Por otro lado, se registró una escudilla honda de La Paya $\left(\mathrm{N}^{\circ}\right.$ ME 833 en la Figura 11) de contorno simple, base plana/indiferenciada, superficie externa marrón pulida e interna con un baño negro que sobrepasa hacia el borde externo, rasgos que resultan estrechamente coincidentes con gran cantidad de escudillas de la Quebrada de Humahuaca (Cigliano 1967; Cremonte 1990-91; Cremonte y Solís 1998).

De El Churcal se identificó una botella $\left(\mathrm{N}^{\circ} 28\right)$ de cuerpo globular, cuello hiperboloide, base plana, asas asimétricas a la altura del diámetro máximo del cuerpo y superficie externa rojiza, aparentemente pulida (Figura 12). Esta vasija muestra estrechas semejanzas con piezas de la región puneña de Jujuy (Figura 12), registradas, por ejemplo, en San Juan Mayo (Lehmann-Nitsche 1904: lám. V A 12), Rinconada (Ambrosetti 1901: fig. 41), Doncellas (Krapovickas 1958-59: 58) y Sansana (Boman 1908: fig. 191 I), y con una de las variantes morfológicas identificadas para la alfarería Yavi (Albeck 2001: foto 3; Ávila 2006: 45-46).

Asimismo, en la muestra se reconocieron dos piezas similares a la alfarería Yocavil Polícromo (Bennett et al. 1948) y su semejante de la región chaco-santiagueña (Figura 13). Una procede de Guitián (Figura 2) y corresponde a un fragmento de una pieza abierta con decoración interior en rojo sobre blanco y exterior en negro sobre rojo, con la aplicación de una figura zoomorfa en el borde ( $\left.\mathrm{N}^{\circ} \mathrm{MAC} 1245\right)$. La otra pieza, procedente de Amaicha (Figura 2), es una vasija de cuerpo globular con cuello

5 Este diseño corresponde a los «ameboidales» de Krapovickas y Aleksandrowicz (1986-87: fig. 9). 

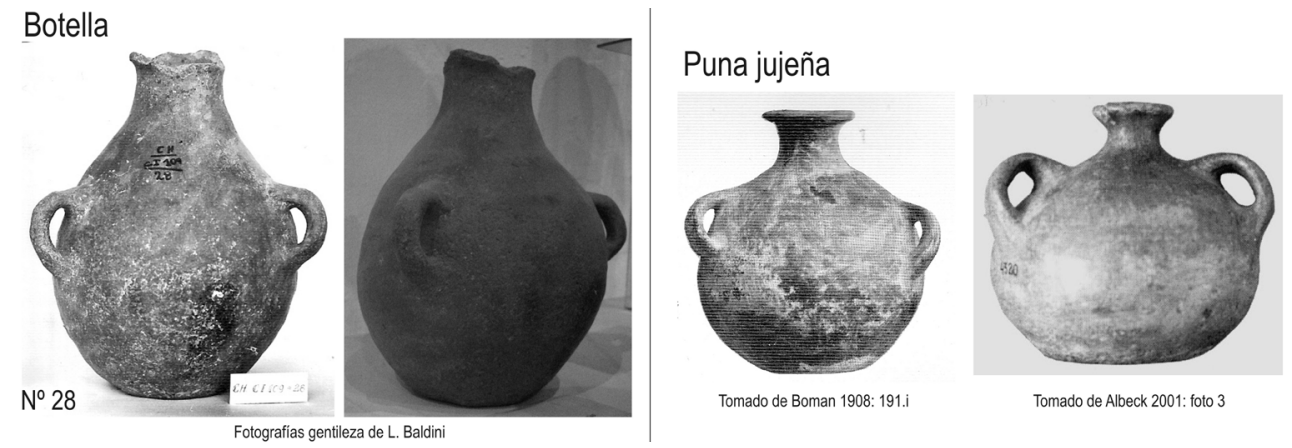

Figura 12: Pieza similar a alfarerías puneñas en la muestra analizada y ejemplares de la puna.
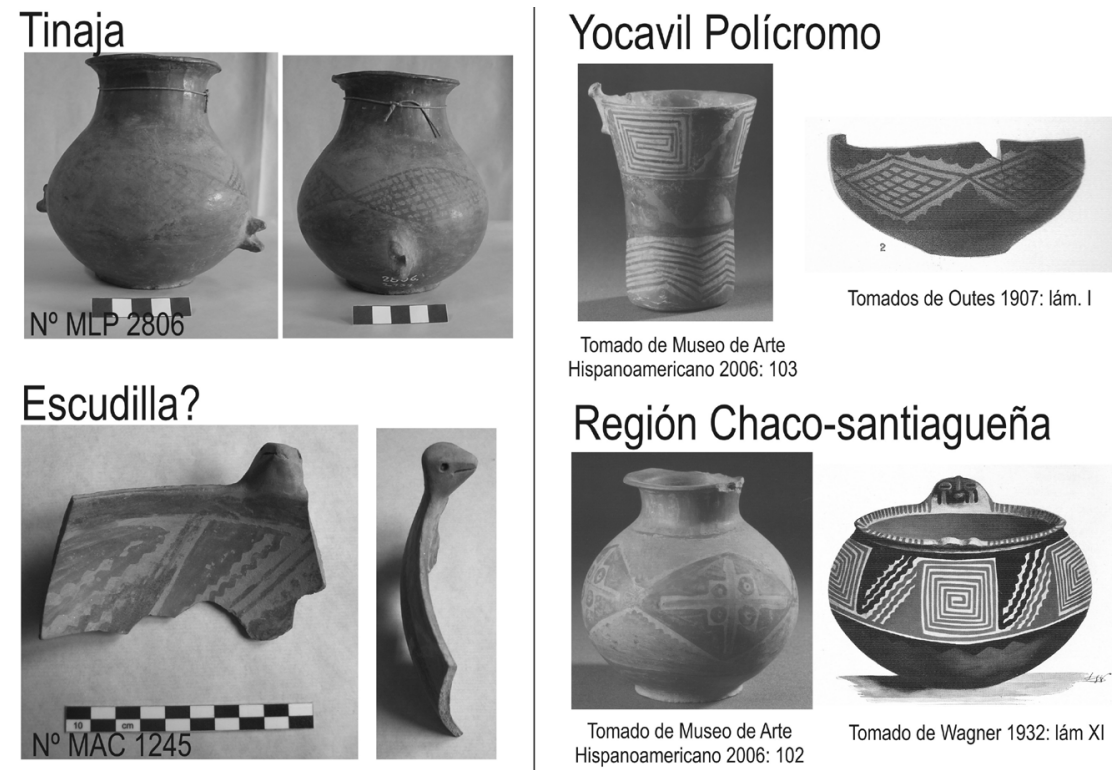

Tomados de Outes 1907: lám. I
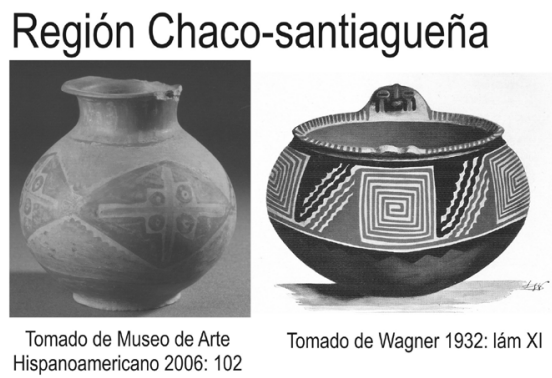

Figura 13: Piezas de similitud con la alfarería Yocavil Polícromo en la muestra analizada, ejemplares de cerámica Yocavil Polícromo y similares de la región Chaco-santiagueña.

y dos pequeñas asas macizas y decoración en negro y blanco sobre rojo con motivos reticulados ( $\mathrm{N}^{\circ}$ MLP 2806).

Por último, se identificó una escudilla ( $\mathrm{N}^{\circ}$ MLP 4154), proveniente de La Poma (Figura 2), que corresponde al estilo Poma Negro sobre Rojo. Si bien este estilo fue reconocido como propio de la Quebrada de Humahuaca (Dillenius 1909; Cigliano y Calandra 1973), no puede considerarse foráneo en el valle Calchaquí en tanto se conoce la existencia de una variante pomeña de manufactura local en el extremo norte del valle (Cremonte y Garay de Fumagalli 1997), pero si resulta indicativo de la exis- 
tencia de vinculaciones que permitieron la circulación de al menos información entre poblaciones del sur de la Quebrada de Humahuaca y del norte del valle Calchaquí.

El segundo gran grupo dentro de la muestra cerámica es el compuesto por aquellas piezas de rasgos locales pero que señalan ciertos vínculos extrarregionales. Este es el caso, dentro del más amplio espectro de la alfarería Santamariana ${ }^{6}$, de las piezas de subtradición Calchaquí, una de las dos propuestas para los pucos santamarianos del valle Calchaquí, semejantes a las del estilo santamariano del valle de Yocavil, en la Provincia de Catamarca (Calderari 1991b). En la muestra, esta subtradición se reconoce, en sus variedades Bicolor y Tricolor, en 71 vasijas de La Paya y Tero, entre las que predominan los cuencos, escudillas hondas, escudillas y platos hondos, acompañados por otras piezas como vasos libatorios y ollas.

También es el caso de la alfarería negra pulida del valle Calchaquí, que en la muestra está representada por 91 ejemplares, mayormente provenientes de La Paya $(\mathrm{N}=69)$ y Tero $(\mathrm{N}=19)$. El análisis de su variabilidad morfológica y su comparación con materiales de otras regiones permitió reforzar su similitud con alfarería de superficies negras pulidas de sitios tardíos de la Quebrada del Toro, en el NO de la Provincia de Salta (Baldini y Sprovieri 2009).

Entre los restantes materiales, no cerámicos, de la muestra, los análisis estilísticos desarrollados permitieron detectar otros tipos de indicadores de circulación interregional. Como elementos de rasgos no locales, se registraron artefactos inka de gran difusión en las provincias como los keros, representados en la muestra por dos ejemplares, uno de los cuales conserva decoración polícroma de motivos geométricos inkaicos, y los tumis, representados por cuatro ejemplares.

Otros artefactos y materiales, aunque sin características necesariamente alóctonas, también resultaron indicadores de circulación. Entre estos se incluyen las tabletas y tubos de rapé, artefactos de hallazgo esporádico en el NOA, que tienen una presencia destacada en la muestra estudiada. El análisis de atributos morfológicos y decorativos en 50 ejemplares del valle Calchaquí permitió reconocer variantes en su forma e iconografia (Sprovieri 2008-09). Al comparar esas variantes con tabletas y tubos de otras regiones se observaron fuertes semejanzas iconográficas y morfológicas entre los ejemplares del valle Calchaquí y los de la región del río Loa, en el Norte de Chile, los de la puna de Jujuy y los de la Quebrada de Humahuaca (Sprovieri 2008-09: tabla 4 y fig. 4 y 5). Si bien existen también coincidencias entre algunas tabletas y tubos de La Paya y otras de San Pedro de Atacama (Norte de Chile), éstas se manifiestan más débiles, tanto en términos de frecuencia como en grado de similitud (Sprovieri 2008-09: tabla 4).

Otro ejemplo son los torteros. En su gran mayoría, se encuentran fabricados en madera $(\mathrm{N}=96)$, aunque existen algunos ejemplares en piedra $(\mathrm{N}=17)$, hueso $(\mathrm{N}=5)$ y cerámica $(\mathrm{N}=4)$. Por medio de su morfología y decoración, se reconocieron 17 variantes en la muestra del valle Calchaquí (Sprovieri 2010a: lám. 74). Su comparación con torteros de otras regiones indicó que tres de esas variantes, una cruciforme (variante 8), otra de contorno circular y con sectores semicirculares con grabados (variante 9) y, especialmente, la variante 5 en forma de flor de pétalos subrectangulares

6 Esta tradición estilística es característica de las sociedades tardías conocidas como Santa María que ocuparon distintos valles del NOA, entre ellos el Calchalquí. 


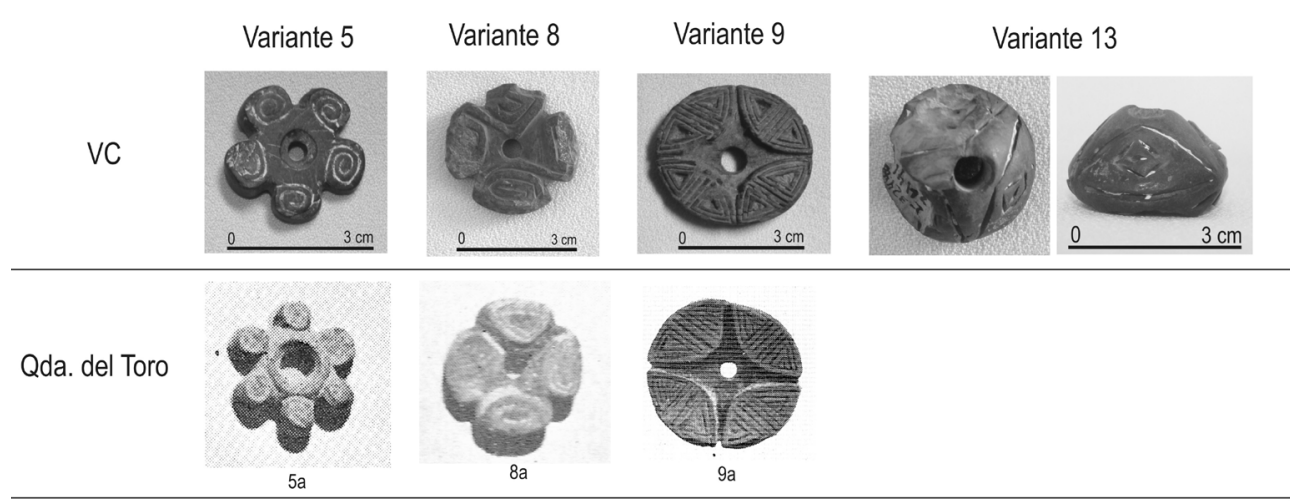

Andalgalá

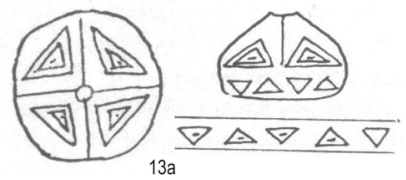

Figura 14: Comparación de las principales variantes de torteros en la muestra analizada con las de distintas regiones del NOA. (Referencias: 5a y 8a tomados de Cigliano 1973: fig. 73, 9a tomado de Boman 1908: fig. 75i y 13a tomado de Williams 1983: fig. 1).

(simil engranaje), presentan semejanzas con torteros de la Quebrada del Toro (Figura 14). Por su parte, la variante 13 , de forma cónica con incisiones y manufacturada en cerámica, muestra estrechas similitudes con piezas del asentamiento inkaico de $\mathrm{Po}$ trero Chaquiago, en Andalgalá, centro de Catamarca (Figura 14).

Otro indicador resultó ser la iconografía grabada en calabazas. El único ejemplar pirograbado de la muestra ( $\mathrm{N}^{\circ}$ ME 618) presenta el motivo santamariano de serpiente bicéfala (Figura 15A). Fuera de la región calchaquí, se han hallado calabazas con motivos serpentiformes en contextos tardíos de la región del río Loa, Atacama y la puna de Jujuy (Ambrosetti 1901; Oyarzún 1929; Rydén 1944; Durán 1976; Hernández Llosas 1983-85) (Figura 15B). Entre ellas, una calabaza procedente de Chiu Chiu, en la región del río Loa, presenta fuerte similitud con la pieza que forma parte de la muestra (Figura 15C).

Además, en la bibliografía se registraron otras dos calabazas del valle Calchaquí que exhiben motivos de escutiformes propios de la iconografía santamariana (Figura 15D). Estos motivos también se presentan en calabazas de la región del Loa (Figura $15 \mathrm{E}$ ), en el arte rupestre de esa misma región (Berenguer 2004: fig. 9.27) y de la puna argentina (Tarragó et al. 1997: fig. 4), y en placas metálicas del Norte de Chile (Llagostera 2004: 179). Otro motivo relevante son los suris muy estilizados, característico de la decoración de la cerámica Casa Morada Polícromo (Bennett et al. 1948) (Figura 15F), que se observan en calabazas de la región del Loa, Atacama y la puna de Jujuy (Oyarzún 1929; Rydén 1944; Durán 1976; Alfaro y Gentile 1978; Hernández Llosas 1983-85; Llagostera 2004) (Figura 15G y H).

Como vía de análisis complementaria a los estudios estilísticos, se desarrollaron análisis de procedencia específicos sobre las obsidianas y maderas de la muestra; materiales que eran factibles de estudio considerando las posibilidades de las técnicas analíticas y de intervención sobre colecciones museográficas. 
A)
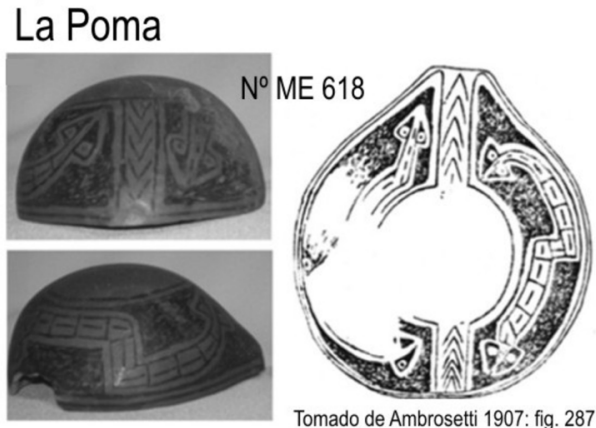

Tomado de Ambrosetti 1907: fig. 287

D)

Pucarilla
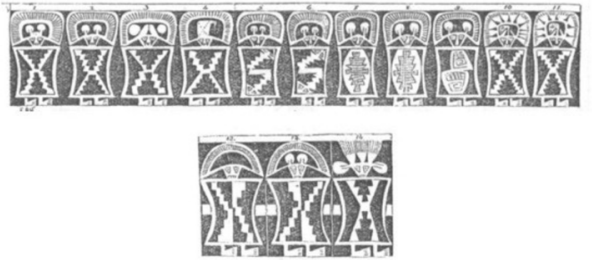

Tomados de Ambrosetti 1901: fig. 53 y 54

F)

\section{Casa Morada Polícromo}

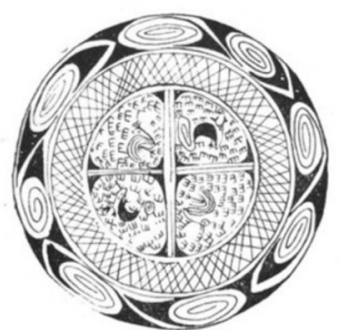

Tomado de Ambrosetti 1907: fig. 38
B)

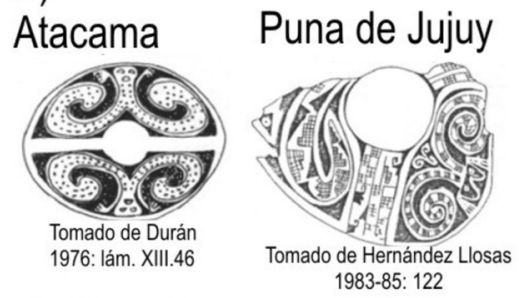

C) Chiu Chiu

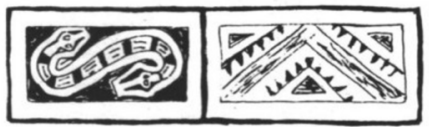

Tomado de Durán 1976: lám. XIII.45

\section{E) Región del río Loa}

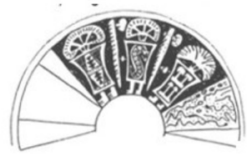

Tomado de Rydén 1944: fig. 80.R

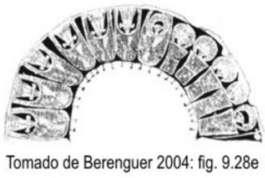

G) Norte de Chile
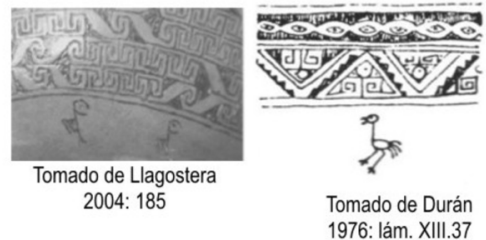

H) Puna de Jujuy

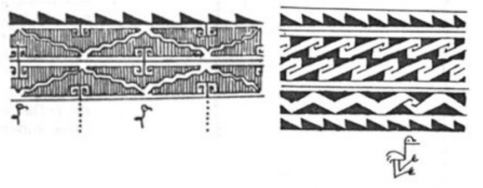

Tomado de Hernández Llosas 1983-85: 95 y 106

Figura 15: Iconografía en calabazas y cerámica del valle Calchaquí y motivos similares en calabazas de otras regiones del NOA y el Norte de Chile. 
Cuadro 2: Resultados de los análisis de Fluorescencia de Rayos $\mathrm{X}$

\begin{tabular}{llll}
\hline N$^{\mathbf{0}}$ de muestra & $\mathbf{N}^{\mathbf{0}}$ de pieza & Procedencia & \multicolumn{1}{c}{ Fuente } \\
\hline MLS016 & 534.1 & El Churcal & Salar del Hombre Muerto \\
MLS017 & 595.3 & El Churcal & Ona \\
MLS018 & 536 & El Churcal & Salar del Hombre Muerto \\
MLS019 & 1085 & La Paya & Ona \\
MLS020 & 1087 & La Paya & Salar del Hombre Muerto \\
MLS021 & 1200 a & La Paya & Salar del Hombre Muerto \\
MLS022 & 1200 b & La Paya & Ona \\
MLS023 & 1283 & La Paya & Laguna Blanca/Zapaleri \\
MLS024 & 1598 & La Paya & Ona \\
MLS025 & 1651 & La Paya & Laguna Blanca/Zapaleri \\
MLS026 & 1749 & La Paya & Ona \\
MLS027 & 1798 & La Paya & Ona \\
MLS028 & 2038 & La Paya & Ona \\
\hline
\end{tabular}

La procedencia de las obsidianas se abordó a través de la técnica de Fluorescencia de Rayos X, la cual se aplicó sobre 13 muestras de La Paya y El Churcal, que completan información preexistente sobre las fuentes de obsidianas utilizadas en otros sitios del valle Calchaquí (Yacobaccio et al. 2004; Sprovieri y Baldini 2007; Sprovieri y Glascock 2007; Chaparro 2013). Los resultados indican que las obsidianas provienen de tres fuentes ${ }^{7}$ (Cuadro 2). En La Paya y El Churcal se utilizaron obsidianas de las fuentes Ona y Salar del Hombre Muerto en la puna de Catamarca, y en La Paya además de la fuente Laguna Blanca/Zapaleri en la puna norte, cercana a la zona donde limitan Argentina, Bolivia y Chile.

En cuanto a las maderas, los estudios realizados sobre 45 piezas de La Paya permitieron un primer acercamiento a la determinación de los géneros y/o especies utilizados y de sus zonas de origen (Sprovieri y Rivera 2014). Mediante análisis xilológicos se distinguieron nueve grupos generales de maderas afines según las características anatómicas. La gran mayoría de los artefactos se habrían confeccionado en maderas de disponibilidad local en el valle Calchaquí, pero un $26 \%$ se reparte en seis grupos que presentan rasgos anatómicos similares a maderas que se desarrollan en los bosques orientales del NOA o yungas, como madera de lianas, seibo, curupí, peteribí, nogal criollo y cebil (Sprovieri y Rivera 2014). Más recientemente, nuevos análisis y de mayor profundidad sobre las maderas de artefactos de El Churcal confirman la utilización de especies no locales, originarias de la yungas, por parte de las poblaciones calchaquíes tardías (Baldini et al. 2013).

Entre los demás tipos de materiales de la muestra, la consideración de su procedencia permitió confirmar la presencia de dos valvas del género Pecten y una del género Scurria, propios del Océano Pacífico (Sprovieri 2010a). Por su parte, los objetos de metal calchaquíes se encontrarían mayormente fabricados en bronce estañífero (Ambrosetti 1907: 412-413). El cobre tiene cierta disponibilidad regional (Angelelli et al. 1970; Secretaría de Minería y Recursos Energéticos 2007), no así el estaño que se encuentra disponible más puntualmente, en distintas zonas de la puna norte de Jujuy, por ejemplo (Angelelli et al. 1970). Por último, la utilización de otros recursos de las

7 Mapa con localización de fuentes de obsidiana del NOA disponible en Elías y Escola 2010. 
yungas está evidenciada por la presencia de cascabeles manufacturados en frutos de nogal criollo, árbol que se desarrolla en esa región (Cabrera 1971), e indirectamente por la presencia de las tabletas y tubos de rapé, que revelan el consumo por parte de las poblaciones calchaquíes de sustancias alucinógenas que se extraen de especies propias de los bosques orientales del NOA (Pérez Gollán y Gordillo 1993).

\section{Sobre contextos y cronología}

Como se mencionó, los materiales estudiados proceden, en gran parte, de excavaciones de contextos funerarios, así como de otros contextos de tipo residencial. El análisis de los contextos de hallazgo ha permitido una segregación cronológica de las evidencias de circulación interregional, fundamentalmente a partir de la existencia o no de asociación con materiales inkaicos, pero también con base en la realización de algunos fechados sobre materiales específicos.

Los estilos alfareros y vasijas de rasgos foráneos muestran una muy fuerte asociación con momentos inkaicos, ya que el $90,66 \%$ poseen rasgos inkaicos y/o se encuentran asociados a contextos con materiales inkaicos. La única excepción es la botella de asas asimétricas procedente de una cista de El Churcal, en la cual no fueron registrados objetos de tipo inka, al igual que en el resto de las excavaciones del asentamiento (Raffino 1984).

Por otro lado, se observa una estrecha relación entre el complejo de rapé y contextos sin materiales inkaicos, lo que sucede en el $87,2 \%$ de las tabletas y tubos estudiados. Pero además, dos fechados radiocarbónicos realizados sobre la madera de estos artefactos los ubican cronológicamente dentro del Período de Desarrollos Regionales (Cuadro 3).

Cuadro 3: Fechados de artefactos de madera de La Paya

\begin{tabular}{lcccll}
\hline $\begin{array}{c}\text { Laboratorio } \\
\text { y no de muestra }\end{array}$ & $\begin{array}{c}\text { Años }{ }^{14} \mathbf{C} \\
\text { AP }\end{array}$ & \multicolumn{2}{c}{ Años d.C. calibrados* } & Procedencia & Material fechado \\
\cline { 3 - 4 } & (1 sigma) & (2 sigma) & & \\
\hline AA85654 & $680 \pm 35$ & $1300-1389$ & $1291-1394$ & $\begin{array}{l}\text { La Paya - } \\
\text { Tumba 121 }\end{array}$ & $\begin{array}{l}\text { Madera de tubo de rapé } \\
\left(N^{\circ} \text { ME 1141) }\right.\end{array}$ \\
AA85655 & $699 \pm 35$ & $1293-1385$ & $1285-1391$ & $\begin{array}{l}\text { La Paya - } \\
\text { Tumba 88a }\end{array}$ & $\begin{array}{l}\text { Madera de tableta de rapé } \\
\left(N^{\circ} \text { ME 1129) }\right.\end{array}$ \\
\hline
\end{tabular}

* Las calibraciones se realizaron con el programa Calib Rev. 5.1 beta (Stuiver et al. 2005) utilizando la calibración para el hemisferio sur (shcal04.14c) (McCormac et al. 2004).

El resto de las evidencias de circulación interregional se asocian a contextos con y sin materiales inkaicos, sin una tendencia tan clara hacia uno u otro tipo de posición cronológica (Sprovieri 2010a). Sin embargo, en particular los torteros similares a los de Potrero Chaquiago y la iconografía de suris en calabazas se encuentran más estrechamente vinculados con momentos inkaicos.

\section{Circulación interregional tardía en el valle Calchaquí}

Desde hace tiempo las investigaciones arqueológicas en el valle Calchaquí vienen aportando datos, con distintos grados de profundidad, sobre los procesos de interac- 
ción interregional tardía (Tarragó y De Lorenzi 1976; González y Díaz 1992; Calderari 1991a y b; Gifford 2003; Baldini et al. 2004; Williams 2004; Yacobaccio et al. 2004, entre otros) o, incluso en un caso, postulando un bajo desarrollo de los contactos entre el valle y otras regiones durante el Período de Desarrollos Regionales (Acuto et al. 2008).

Los datos aquí presentados, producto de un estudio sistemático con inclusión de distintas líneas de evidencia, abogan consistentemente por la especificidad del fenómeno de circulación de bienes e ideas en el valle Calchaquí durante los últimos siglos prehispánicos, planteando la efectiva inserción de las poblaciones calchaquíes en contextos de interacción interregional de diverso alcance y singularidad. Estos datos, considerados en conjunto con los ya existentes, permiten avanzar en el planteamiento de las esferas y circuitos por los que se habrían movilizado bienes materiales y simbólicos hacia y desde el valle, y en el reconocimiento de sus variaciones en el tiempo (Figura 16).

Durante el Período de Desarrollos Regionales, las sociedades del valle Calchaquí se muestran fuertemente articuladas y vinculadas con aquellas del valle de Yocavil, más al sur, en tanto ámbitos que se constituyen en el espacio de desarrollo de la entidad sociocultural Santamariana (Tarragó 1970, 1974, 1980; Tarragó y De Lorenzi 1976; Tarragó et al. 1997). Estas vinculaciones muestran continuidad en el tiempo, manifestándose en la época inka por la presencia, limitada, de los estilos alfareros Famabalasto Negro Grabado, Famabalasto Negro sobre Rojo y Yocavil Polícromo en sitios y contextos inkaicos del valle Calchaquí (González y Díaz 1992; Palamarczuk 2011). Con los valles orientales de Salta, otro sector del ámbito santamariano, sólo se insinúan ciertas vinculaciones por la presencia de alfarería santamariana y de fragmentos de cerámica negra pulida, aparentemente similar a la del valle Calchaquí (Tarragó 1974; Alfaro y Navamuel 1979; Tartusi y Núñez Regueiro 2003; Mulvany et al. 2007; Baldini y Sprovieri 2009).

Más hacia el oriente, la confirmación de la presencia de madera posiblemente de lianas, cebil y nogal en el valle Calchaquí, junto a los cascabeles en frutos de nogal y el consumo de sustancias psicoactivas sugerido por tabletas y tubos, señala que las conexiones de las sociedades calchaquíes en el Período de Desarrollos Regionales alcanzan la región de las yungas. Durante la época inka, estas vinculaciones, que permitieron el ingreso de recursos y materias primas desde el este, aparentemente se mantienen, en tanto que se registra para esta época la presencia en el valle de maderas posiblemente de seibo, curupí y peteribí y de frutos de nogal.

En otra dirección, hacia el oeste, la participación de las sociedades calchaquíes en circuitos que comprenden diversos sectores de la región puneña durante los Desarrollos Regionales ha sido señalada a partir del uso de obsidiana de distintas fuentes por dichas sociedades (Yacobaccio et al. 2004; Sprovieri y Baldini 2007; Sprovieri y Glascock 2007; Chaparro 2013). A la utilización de materiales de la fuente Quirón, ubicada en la puna norte de Salta, y de las fuentes Ona y Laguna Cavi, en la puna de Catamarca, se suma, según los nuevos resultados aquí presentados, el empleo de obsidiana de la fuente Salar del Hombre Muerto, también localizada en esta última zona. Por su parte, la utilización de obsidiana de la fuente Laguna Blanca/Zapaleri indica que esas vinculaciones incluyen el sector central de la puna de Jujuy, como 


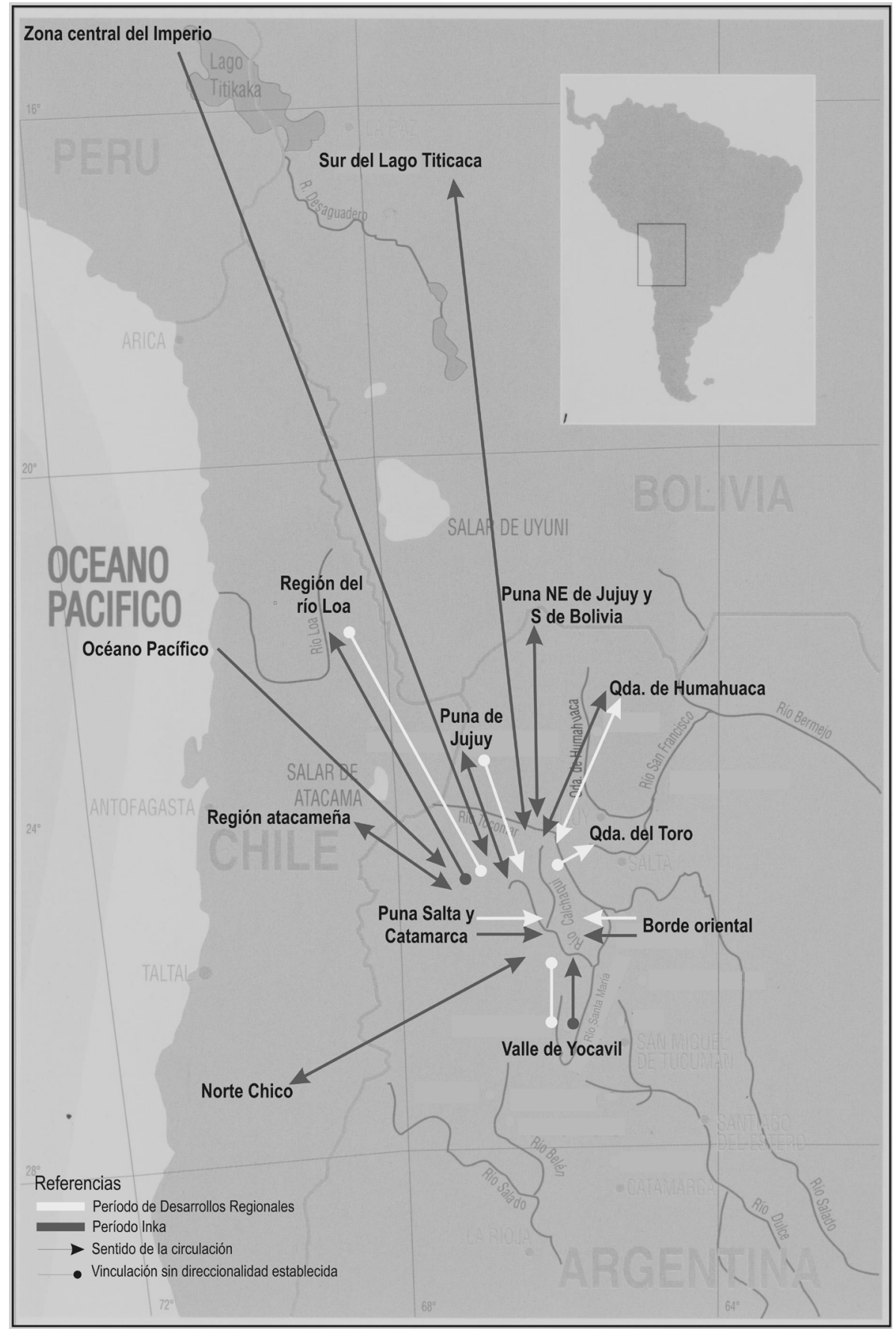

Figura 16: Esquema de las vinculaciones entre en valle Calchaquí y otras regiones de los Andes Centro-sur en el Período de Desarrollos Regionales y el Período Inka (mapa modificado de Museo Chileno de Arte Precolombino 1994). 
también lo manifiesta el hallazgo de una botella de asas asimétricas en el sitio El Churcal, y que el estaño usado en la producción metalúrgica puede provenir de este sector. En momentos posteriores, durante el Período Inka, se ha registrado una utilización de estos mismos recursos y fuentes, lo cual sugiere una aparente continuidad de los circuitos de aprovisionamiento previamente establecidos, al menos con relación a la obsidiana para la cual existen mayores datos (Sprovieri y Glascock 2007; Chaparro 2013).

Además, y en términos más generales, el registro de iconografía santamariana en el arte rupestre de Antofagasta de la Sierra estaría señalando la circulación de ciertos motivos estilísticos desde el ámbito santamariano en sentido amplio hacia la puna de Catamarca en momentos tardíos (Tarragó et al. 1997; Aschero 1999).

Hacia el norte, la existencia de circuitos que vincularon significativamente el sector norte del valle Calchaquí con la Quebrada del Toro y el sur de la Quebrada de Humahuaca durante los Desarrollos Regionales se encuentra sugerida por la presencia en el extremo norte del valle de alfarería Poma Negro sobre Rojo (Dillenius 1909) y Tilcara Negro sobre Rojo de la Quebrada de Humahuaca (DeMarrais 2001; Gifford 2003) y Borravino sobre Naranja de Tastil, de la Quebrada del Toro (Cigliano y Calandra 1973; Pollard 1983). También apoyan esto la similitud entre la alfarería negra pulida del valle Calchaquí y piezas de la Quebrada del Toro (Baldini y Sprovieri 2009), y las semejanzas aquí señaladas en la forma y decoración de torteros del valle y de Tastil.

A estas evidencias se suma la presencia de pucos Poma pomeños en el sitio Volcán (Cremonte y Solís 1998), en el sector sur de la Quebrada de Humahuaca, y de cerámica del valle Calchaquí en Tastil (Cigliano y Calandra 1973), además de un molde de disco estilísticamente santamariano (Cigliano 1973), que podría reforzar esa conexión.

En la época Inka, las vinculaciones que alcanzan regiones al norte del valle toman nuevas dimensiones. Las evidencias de conexiones con la Quebrada de Humahuaca ya no se ven restringidas al extremo norte del valle, sino que comienzan a manifestarse en su sector medio, particularmente en La Paya, por la presencia de piezas de características estilísticas quebradeñas. Asimismo, se plantean vinculaciones que ahora también comprenden la zona de la puna noreste de Jujuy y el sur de Bolivia por la fuerte influencia del estilo Yavi en la conformación del estilo Casa Morada Polícromo (Tarragó 1984), por la presencia de cerámica Yavi alóctona en el valle (Williams 2004) y de piezas con características estilísticas Yavi en La Paya detalladas más arriba.

Conexiones aún más al norte, que incluyen el Altiplano de Bolivia, en particular el área sur del Lago Titicaca, se evidencian por la presencia de alfarería Inka-Pacajes en el valle Calchaquí (Pollard 1983; Baldini 1994; Williams 2004) y la similitud arriba señalada entre las representaciones de peces de un aribaloide de la Casa Morada de La Paya con las de alfarería de la zona de La Paz. Asimismo, por la presencia de vasijas Casa Morada Polícromo y de estilo santamariano del valle Calchaquí en el área de Cochabamba, Bolivia (Raffino 1981; Lorandi y Cremonte 1991).

Con respecto al Norte de Chile, las fuertes vinculaciones propuestas para la primera época aldeana (200 a.C.-600 d.C.) entre el valle Calchaquí y los oasis atacameños 
parecen perder dinamismo durante el Período de Desarrollos Regionales (Serrano 1963; Tarragó 1984, 1996; Pérez Gollán y Gordillo 1994; Torres 1998; Baldini 2007). Sin embargo, para esta última época existen algunos indicios de la participación de las sociedades calchaquíes en circuitos que alcanzaron un área del norte chileno en particular, la región del río Loa. Así lo indicarían las semejanzas detectadas en la iconografía relativa al complejo alucinógeno de ambas regiones (Sprovieri 2008-09) y, para la época tardía en general, la presencia de iconografía santamariana en calabazas y el arte rupestre del río Loa (Durán 1976; Tarragó et al. 1997; Berenguer 2004).

En cambio, durante el Período Inka, los circuitos que vincularían el valle Calchaquí y el Norte de Chile, especialmente San Pedro de Atacama, parecen recuperar el impulso de momentos más tempranos. Así lo sugiere la presencia en el valle de cerámica color borravino, similar a un tipo del norte chileno (González y Díaz 1992), o del aribaloide de estilo Diaguita Chileno descrito antes y, del lado de Chile, de piezas de estilo Casa Morada Polícromo en los oasis de Atacama (Tarragó 1970; Tarragó y De Lorenzi 1976; Uribe 2002) y en el Norte Chico (Ambrosetti 1907; Salas 1945; Tarragó et al. 1997), y de iconografía de suris en calabazas de la región del río Loa y Atacama, asimilables a los suris del estilo Casa Morada Polícromo como se indicó más arriba. Otras evidencias de esta situación se relacionan con el ámbito santamariano en sentido amplio, como el hallazgo de iconografía santamariana en placas metálicas de Catarpe y Taltal (Tarragó et al. 1997), en el arte rupestre de sitios del río Loa (Berenguer 2004) y en calabazas pirograbadas de la región atacameña (Rydén 1944; Durán 1976).

Por último, la determinación de la pertenencia a los géneros Pecten y Scurria de valvas halladas en algunos contextos sin materiales inkaicos del valle Calchaquí indican vínculos que alcanzan el Océano Pacífico. Este tipo de bien, considerado estrechamente asociado a la presencia imperial en la región, fue fehacientemente registrado en contextos de época inka de La Paya y Potrero de Payogasta (Ambrosetti 1907; Boman 1908; De Lorenzi y Díaz 1977).

Finalmente, es importante considerar que la ocupación inkaica del valle Calchaquí involucró fundamentalmente la incorporación de las sociedades locales en circuitos de relaciones que las vinculaban al Imperio y su centro. Este proceso de conquista y anexión implicó la difusión y aplicación de una amplia gama de estándares imperiales a distintos aspectos del modo de vida de las sociedades conquistadas, provocando modificaciones en muchas prácticas autóctonas.

En el valle Calchaquí, como en muchas otras regiones del NOA, esto generó una variedad de nuevos materiales y prácticas que remiten a vínculos más o menos directos establecidos con la sociedad inka. Entre ellos se incluyen la presencia de instalaciones imperiales de características arquitectónicas y diseño espacial inkaico (Raffino 1981; Hyslop 1990; González y Díaz 1992; Williams y D’Altroy 1998; Acuto 1999; D'Altroy et al. 2000; Gifford y Acuto 2002), la construcción de tramos de capacñam (Raffino 1981; Hyslop y Díaz 1983; Hyslop 1984), nuevas prácticas rituales evidenciadas en la construcción de santuarios y otros sitios de altura (D'Altroy et al. 2000; Jacob y Leibowicz 2007; Vitry 2008), el desarrollo de actividades artesanales, productivas y de almacenaje vinculadas a requerimientos imperiales (Tarragó y De Lorenzi 1976; Raffino 1981; Calderari 1991b; Calderari y Williams 1991; Acuto 
1994; Earle 1994; D’Altroy et al. 2000; DeMarrais 2001; Tarragó y González 2003; Williams 2004; Williams et al. 2005) y el traslado de mitmaqkunas al valle (Lorandi y Cremonte 1991; Williams 2004).

En particular, con relación a la muestra estudiada, se registró un $6,62 \%(68 / 1027)$ de materiales que responden estilísticamente a cánones imperiales, porcentaje que se duplica al considerar la muestra cerámica aisladamente $(13,39 \%, 62 / 463)$. Pero además, es relevante la presencia, aunque escasa, de objetos de origen cuzqueño en el valle Calchaquí, entre ellos dos ollitas de dos asas procedentes de la Casa Morada de La Paya (Ambrosetti 1907; Boman 1908; Tarragó y De Lorenzi 1976).

En síntesis, hasta el momento la información con que se cuenta muestra que durante el Período de Desarrollos Regionales las poblaciones calchaquíes participaron en distintos circuitos de interacción interregional con sociedades de ámbitos ecológica y culturalmente diversos. Ello ocasionó el ingreso y egreso de diversos materiales que abarcaron recursos y materias primas de la región puneña y de las yungas, a la vez que bienes e ideas que se movilizaron por esferas que abarcaron otras áreas del Noroeste argentino, como el valle de Yocavil, la Quebrada del Toro y sur de la Quebrada de Humahuaca, el Norte de Chile (especialmente la región del río Loa) y aparentemente también el Océano Pacífico.

A partir de la llegada del Imperio Inka al valle Calchaquí, la circulación interregional de bienes, recursos e ideas muestra continuidades y cambios. Aparentemente no hay rupturas, sino más bien una intensificación y ampliación de ciertas esferas de circulación previas, como la que abarca la Quebrada de Humahuaca o la costa pacífica, a la vez que se manifiestan otras esferas que comprenderían nuevas zonas, como el área Yavi, el Altiplano boliviano, el Norte chileno (especialmente San Pedro de Atacama) y áreas centrales del Imperio. Por estas esferas de circulación nuevas o ampliadas parecen haberse movilizado no tanto recursos o materias primas sino fundamentalmente bienes materiales y simbólicos, aparentemente de gran significación en esferas rituales de reproducción de las relaciones sociopolíticas e ideológicas entre el Imperio y las poblaciones nativas, como algunas alfarerías e iconografía de prestigio regional.

Avanzar en la conformación de bases de información concreta sobre la circulación en el pasado a través de estudios sistemáticos de localidades puntuales como el aquí expuesto constituye un marco significativo para generar imágenes más precisas de lo que las prácticas de circulación implicaron para cada sociedad en particular y para entender su inserción en contextos macro regionales y procesos sociohistóricos de mayor alcance.

Agradecimientos: A las autoridades y personal del Museo Etnográfico «J. B. Ambrosetti», Museo Arqueológico «E. Casanova», Museo Arqueológico «P. P. Díaz», Museo de La Plata, American Museum of Natural History, National Museum of the American Indian y National Museum of Natural History, quienes posibilitaron el estudio de las colecciones. Se agradece también a Lidia Baldini por sus comentarios sobre este manuscrito. Esta investigación fue posible gracias a una Beca de Postgrado del CONICET y al financiamiento otorgado a los Proyectos CONICET PIP 5712, UNLP 11/N 461 y UBACYT F034. 


\section{Referencias bibliográficas}

Acuto, Félix

1994 La organización del almacenaje estatal: La ocupación Inka en el sector norte del valle Calchaquí y sus alrededores. Tesis de Licenciatura inédita. Buenos Aires: Facultad de Filosofía y Letras, Universidad de Buenos Aires.

1999 «Paisaje y dominación: La constitución del espacio social en el Imperio Inka», en Sed non Satiata. Teoría Social en la Arqueología Latinoamericana Contemporánea, A. Zarankin y F. A. Acuto, eds., pp. 33-75. Buenos Aires: Ediciones del Tridente.

Acuto, Félix, Claudia Amuedo, Marisa Kergaravat, Ana L. Goldin y Lucila Gamarra

2008 «Experiencias subjetivas en aldeas prehispánicas del valle Calchaquí norte: Arqueología de la vida cotidiana, prácticas y relaciones sociales durante el Período Prehispánico Tardío», en Arqueología del extremo sur del continente americano. Resultados de nuevos proyectos, L. A. Borrero y N. Franco, eds., pp. 11-54. Buenos Aires: CONICET-IMHICIHU.

Albeck, María E.

2001 «La puna argentina en los períodos medio y tardío», en Historia argentina prehispánica, Tomo I, E. Berberian y A. Nielsen, eds., pp. 347-388. Córdoba: Editorial Brujas.

Alfaro, Lidia y Margarita Gentile

1978 «Los mates pirograbados de la cuenca del río Doncellas». Antiquitas №26-27: $1-11$.

Alfaro, Lidia y Ercilia NAVAmuel

1979 «Investigación arqueológica en Tinti (Salta)». Relaciones de la Sociedad Española de Antropología 13: 61-83.

Ambrosetti, Juan B.

1901 «Antigüedades calchaquíes. Datos arqueológicos sobre la Provincia de Jujuy (República Argentina)». Anales de la Sociedad Científica Argentina 53-53: 3-97.

1902 «El sepulcro de La Paya recientemente descubierto en los Valles Calchaquíes (Provincia de Salta)». Anales del Museo Nacional de Buenos Aires 8 (Ser. $3^{\mathrm{a}}$, t/ 1): 119-148.

1907 «Exploraciones arqueológicas en la ciudad prehistórica de La Paya (Valle Calchaquí, Pcia. de Salta)». Revista de la Universidad de Buenos Aires 8: 5-534.

Ampuero, Gonzalo

1989 «La cultura Diaguita Chilena», en Prehistoria: desde sus orígenes hasta los albores de la Conquista, J. Hidalgo, V. Schiappacasse, H. Niemeyer, C. Aldunate e I. Solimano, eds., pp. 277-287. Santiago de Chile: Editorial Andrés Bello.

Angelelli, V., J. Fernandez Lima, A. Herrera y L. Aristarain

1970 Descripción del Mapa Metalogenético de la República Argentina. Minerales Metaliferos. Buenos Aires: Dirección Nacional de Geología y Minería.

Ardissone, Romualdo

1940 «La instalación indígena en el valle Calchaquí, a propósito del Pucará de Palermo». Anales del Instituto de Etnografía Americana 1: 169-89. 
Aschero, Carlos

1999 «El arte rupestre del desierto puneño y el noroeste argentino», en Arte Rupestre en los Andes de Capricornio, J. Berenguer R. y F. Gallardo I., eds., pp. 97-135. Santiago de Chile: Museo Chileno de Arte Precolombino y Banco de Santiago.

Ávila, María F.

2006 Un mundo morado sobre ante. Estudio sobre el estilo cerámico Yavi de la puna oriental de Jujuy. Tesis de Licenciatura inédita. Buenos Aires: Facultad de Filosofía y Letras, Universidad de Buenos Aires.

BALDINI, Lidia

1994 «Animaná. Tambo inca en el valle Calchaquí», en XI Congreso Nacional de Arqueología Argentina, Revista del Museo de Historia Natural de San Rafael 13 (1/4), I: 188. San Rafael, Mendoza.

2007 «Cancha de Paleta, un cementerio del Periodo Formativo en Cachi (Valle Calchaquí, Salta) ». Cuadernos FHYCS 32: 13-33.

BALDini, Lidia, Elvira I. BAFFi, Laura Quiroga y Virginia Villamayor

2004 «Los Desarrollos Regionales en el valle Calchaquí, Salta». Relaciones de la Sociedad Argentina de Antropología 29: 59-80.

BALDINI, Lidia y Marina SPROVIERI

2009 «Vasijas negras pulidas. Una variedad de la cerámica tardía del valle Calchaquí». Estudios Atacameños 38: 21-38.

BAldini, Lidia, Marina Sprovieri y Stella M. Rivera

2013 Uso y circulación de maderas en contextos tardios del valle Calchaquí, Salta. Ponencia presentada en el XVIII Congreso Nacional de Arqueología Argentina. Universidad Nacional de La Rioja.

Balfet, Hélène, Marie-France Fauvet-Berthelot y Susana Monzon

1983 Pour la normalisation de la description des poteries. París: Centre National de la Recherche Scientifique.

Bennett, Wendell C., Everett Bleiler y Frank Sommer

1948 «Northwest Argentine Archaeology». Yale University Publications in Anthropology $\mathrm{N}^{\mathrm{o}} 38$. New Haven.

Berenguer, José

2004 Caravanas, interacción y cambio en el Desierto de Atacama. Santiago de Chile: Sirawi Ediciones.

BOMAN, Eric

1908 Antiquités de la région andine de la République Argentine et du Désert D’atacama. París: Imprimerie Nationale.

Bregante, Odilia

1926 Ensayo de clasificación de la cerámica del Noroeste Argentino. Buenos Aires: Editorial Ángel Estrada y Cía.

CABrera, Ángel

1971 «Fitogeografía de la República Argentina». Boletín de la Sociedad Argentina de Botánica 14 (1-2): 1-43.

CALDERARI, Milena

1991a «Estilos cerámicos incaicos de La Paya», en Actas del XI Congreso Nacional de 
Arqueología Chilena, Tomo 2, pp. 151-164. Santiago de Chile: Museo Nacional de Historia Natural, Sociedad Chilena de Arqueología.

1991b «El concepto de estilo en Ceramología: la Tradición Estilística Santamariana en los pucos de La Paya», en El Arte rupestre en la Arqueología Contemporánea, M. Podestá, M. I. Hernández Llosas y S. Renard de Coquet, eds., pp. 1-13. Buenos Aires: Edición de M. Podestá.

Calderari, Milena y Verónica Williams

1991 «Re-evaluación de los estilos cerámicos incaicos en el Noroeste Argentino». Comechingonia 9 ( $\mathrm{N}^{\circ}$ especial 2): 75-96.

Chaparro, María G.

2013 «Preferencias en el manejo cotidiano de rocas. Los artefactos líticos de los asentamientos estatales del sur de la Quebrada de Humahuaca y el valle Calchaquí medio (Argentina)», en Al Borde del Imperio. Paisajes sociales en áreas periféricas del Qollasuyu, V. Williams y M. B. Cremonte, eds., pp. 273-309. Buenos Aires: Universidad de Buenos Aires.

Cigliano, Eduardo M.

1967 «Investigaciones antropológicas en el yacimiento de Juella (Dep. de Tilcara, Provincia de Jujuy)». Revista del Museo de La Plata (Nueva Serie), Sección Antropología 6: 123-249.

1973 «Madera, Metal, Hueso y Piedra», en Tastil. Una ciudad preincaica argentina, Capítulo V, E. M. Cigliano, dir., pp. 163-228. Buenos Aires: Ediciones Cabargon.

Cigliano, Eduardo M. y Horacio Calandra

1973 «Cerámica», en Tastil. Una ciudad preincaica argentina, E. M. Cigliano, dir., pp. 121-162. Buenos Aires: Ediciones Cabargon.

CoRnely, Francisco L.

1947 «Influencia inkaica en la cerámica diaguita chilena». Publicaciones de la Sociedad Arqueológica de La Serena, Boletín N³: 10-19.

Cremonte, María B.

1990-91 «Análisis de muestras cerámicas de la Quebrada de Humahuaca». Avances en Arqueología 1: 7-42.

Cremonte, María B. y Mercedes Garay de Fumagalli

1997 El enclave de Volcán en las vinculaciones transversales de la región meridional del Valle de Humahuaca (Noroeste de Argentina). 49 Congreso Internacional del Americanistas (ICA), Quito, Ecuador. http://www.naya.org.ar/congresos/ contenido/49CAI/Cremonte.htm.

Cremonte, María B. y Natalia Solís

1998 «La cerámica del Pucará de Volcán: variaciones locales y evidencias de interacción», en Los desarrollos locales y sus territorios. Arqueología del NOA y sur de Bolivia, M. B. Cremonte, comp., pp. 155-196. San Salvador de Jujuy: EdiUNJu.

Cremonte, María B., Irma L. Botto, Alba. M. Díaz, Raúl Viña y María E. Canafoglia

2007 «Vasijas Yavi-Chicha: distribución y variabilidad a través del estudio de pastas», en Actas del XVI Congreso Nacional de Arqueología Argentina, Revista Pacarina $N^{o}$ Especial Tomo 2, pp. 189-200. San Salvador de Jujuy: FHyCS, UNJu. 
D’Altroy, Terence, Ana M. Lorandi, Verónica Williams, Milena Calderari, Christine Hastorf, Elizabeth DeMarrais y Melissa Hagstrum

2000 «Inka Rule in the Northern Calchaquí Valley, Argentina». Journal of Field Archaeology Vol. 27:1-26.

De Lorenzi, Mónica y Pío P. DíAz

1977 «La ocupación incaica en el sector septentrional del valle Calchaquí». Actas y Memorias IV Congreso Nacional de Arqueología Argentina (primera parte). Revista del Museo de Historia Natural de San Rafael (Mendoza) 2 (1/4):75-88.

DeMarrais, Elizabeth

2001 «La Arqueología del norte del valle Calchaquí», en Historia argentina prehispánica, tomo I, E. Berberian y A. Nielsen, eds., pp. 289-346. Córdoba: Editorial Brujas.

Dillenuis, Juliane

1909 «Observaciones arqueológicas sobre alfarería funeraria de la «Poma» (Valle Calchaquí - Provincia de Salta)». Revista de la Universidad de Buenos Aires 6 (11): 67-86 y $133-152$.

DuRÁn, Eliana

1976 «Calabazas pirograbadas del Departamento del Río Loa y sus correlaciones con áreas vecinas». Revista del Museo de Historia Natural de San Rafael 3 (1/4): 119126.

DYER, Brian

2000 «Systematic Review and Biogeography of the Freshwater Fishes of Chile». Estudios Oceanológicos 19: 77-98.

EARLE, Timothy

1994 «Wealth Finance in the Inka Empire: Evidence from the Calchaquí Valley, Argentina». American Antiquity 59 (3):443-460.

ElíAs, Alejandra M. y Patricia S. Escola

2010 «Viejos y nuevos horizontes: obsidianas entre las sociedades agrícolas-pastoriles del Período Tardío en Antofagasta de la Sierra (provincia de Catamarca, Puna Meridional Argentina)». Revista Española de Antropología Americana 40 (2): 9-29.

GifFORD, Clarence H.

2003 Local Matters: Encountering the Imperial Inkas in the South Andes. Tesis doctoral. Nueva York: Columbia University.

GifFord, Clarence H. y Félix Acuto

2002 «Space, Place and Inka Domination in Northwest Argentina», en Experimental Archaeology: Replicating Past Objects, Behaviors, and Processes, J. R. Mathieu, ed., pp. 95-110. British Archaeological Report, International Series 1035. Oxford: Archaeopress.

GonzÁlez, Alberto R. y Pío P. DíAz

1992 «Notas arqueológicas sobre la Casa Morada». Cuadernos de Arqueología 5: 1345 .

Hernández Llosas, María I.

1983-85 «Las calabazas prehispánicas de la puna centro-oriental (Jujuy, Argentina). Análisis de sus representaciones». Anales de Arqueología y Etnología 38/40: 77-159. 
HysLOP, John

1984 The Inka Road System. Nueva York: Academic Press.

1990 Inka Settlement Planning. Austin: University of Texas Press.

Hyslop, John y Pío P. Díaz

1983 «El camino incaico: Calchaquí-Tastil (N.O. Argentino)». Gaceta Arqueológica Andina 1-6: 6-8.

JACOB, Cristian e Iván LeIBOwiCZ

2007 «Historias de altura. Un poco más cerca del Qosqo», en Actas del XVI Congreso de Arqueología Argentina, Revista Pacarina $N^{o}$ Especial Tomo 2, pp. 539-544. San Salvador de Jujuy: FHyCS, UNJu.

Krapovickas, Pedro

1958-59 «Arqueología de la puna argentina». Anales de Arqueología y Etnología 14-15: 53-113.

Krapovickas, Pedro y Sergio AleKsandrowicz

1986-87 «Breve visión de la cultura Yavi». Anales de Arqueología y Etnología 41-42: 83-127.

LEHMANN-NiTSCHE, Robert

1904 «Catálogo de antigüedades de la Provincia de Jujuy». Revista del Museo de La Plata 11: 73-120.

Llagostera, Agustín

2004 Los antiguos habitantes del salar de Atacama. Prehistoria atacameña. Santiago de Chile: Pehuén Editores.

Lorandi, Ana M. y María B. CRemonte

1991 «Evidencias en torno a los mitmaqkunas incaicos en el N.O. Argentino». Anthropológica 9:212-236.

McCormac, F. G., Alan G. Hogg, Paul G. Blackwell, Caitlin E. Buck, Thomas F.G. Higham y Paula J. ReIMER

2004 «SHCal04 Southern Hemisphere Calibration 0-11.0 cal kyr BP». Radiocarbon 46: 1087-1092.

Mulvany, Eleonora, Elsa M. Mamani, Federico Viveros y Mariana Ilari

2007 «Estilos incaicos del Horizonte Tardío en la región de Lema», en Actas del XVI Congreso Nacional de Arqueología Argentina. Revista Pacarina $N^{o}$ Especial Tomo I, pp. 499-505. San Salvador de Jujuy: FHyCS, UNJu.

Munizaga, Carlos

1957 «Descripción y análisis de la cerámica y otros artefactos de los valles de Lliuta, Azapa y Vitor», en Arqueología chilena, Contribución al estudio de la región comprendida entre Arica y La Serena, R. P. Schaedel, ed., pp. 45-58. Santiago de Chile: Universidad de Chile.

Museo Chileno de Arte Precolombino

1991 Diaguita. Pueblos del norte verde, $2^{\mathrm{a}}$ edición. Santiago de Chile.

1994 Los sueños del jaguar. Imágenes de la puna y la selva argentina. J. Berenguer Rodríguez, ed. Santiago de Chile.

Museo de Arte Hispanoamericano I. Fernández Blanco

2006 Tesoros precolombinos del Noroeste argentino., M. Goretti, ed. y comp. Buenos Aires: Fundación CEPPA. 
Outes, Félix F.

1907 Alfarerías del noroeste argentino. Anales del Museo de La Plata, Tomo I, (segunda serie).

OYARZún, Aureliano

1929 «Las calabazas pirograbadas de Calama». Revista Chilena de Historia y Geografía 62 (66): 82-104.

PALAMARCZUK, Valeria

2011 Un estilo y su época: El caso de la cerámica Famabalasto Negro Grabado del Noroeste Argentino. BAR International Series 2243. Oxford: Archaeopress.

Pérez Gollán, José A. e Inés Gordillo

1993 «Religión y alucinógenos en el antiguo Noroeste Argentino». Ciencia Hoy 4 (22): 50-63.

1994 «Vilca/Uturuncu. Hacia una arqueología del uso de alucinógenos en las sociedades prehispánicas de los Andes del Sur». Cucuilco 1 (1): 99-140.

POLLARD, Gordon

1983 «Nuevos aportes a la prehistoria del valle Calchaquí, Noroeste Argentino». Estudios de Arqueología 3 y 4: 71-92.

Portugal, Maks

1957 «Arqueología de La Paz», en Arqueología Boliviana (Primera Mesa Redonda), C. Ponce Sanginés, dir., pp. 360-391. La Paz: Biblioteca Paceña-Alcaldía Municipal.

RAFFINO, Rodolfo

1981 Los Inkas del Kollasuyu. La Plata: Ramos Americana Editora.

1984 «Excavaciones en El Churcal (Valle Calchaquí, República Argentina)». Revista del Museo de La Plata 7, Antropología 59: 223-263.

Reis, Roberto E., Sven O. Kullander y Carl J. Ferraris, Jr.

2003 Check List of the Freshwater Fishes of South and Central America. Porto Alegre: EDIPUCRS.

RYDÉN, Stig

1944 Contributions to the Archeology of the Rio Loa Region. Göteborg: Erlanders Bocktyryckeri Aktiebolag.

1947 Archaeological Researches in the Highlands of Bolivia. Göteborg: Erlanders Bocktyryckeri Aktiebolag.

SagáRnaga Meneses, Jédu A.

2008 «Alianza y ritualidad en Tiwanaku. Las vasijas pares de Pariti». Chachapuma, Revista de Arqueología Boliviana 4: 31-43.

Salas, Alberto M.

1945 El antigal de Ciénaga Grande (Quebrada de Purmamarca, Prov. de Jujuy). Publicaciones del Museo Etnográfico de la Facultad de Filosofía y Letras, Universidad de Buenos Aires, Serie A, V. Buenos Aires.

Secretaría de Minería y Recursos Energéticos

2007 Minería de Salta: Prospección, producción y exportaciones. Padrón de minas, canteras y cateos. Ministerio de la Producción y el Empleo, Secretaría de Minería y Recursos Energéticos, Gobierno de la Provincia de Salta. Salta: Crisol. 
Serrano, Antonio

1958 Manual de Cerámica Indígena. Córdoba: Editorial Assandri.

1963 Lineas fundamentales de arqueología salteña. Salta: Edición del autor.

SPROVIERI, Marina

2006 Circulación e Interacción en el valle Calchaquí entre el siglo IX y la primera época de contacto con los españoles: Explorando la dinámica social tardía. Informe de avance presentado al CONICET. Ms.

2007 Interacción social en el pasado. Cultura material y paisaje. Monografía final aprobada para el Seminario de Doctorado «Cuerpo, materialidad y espacio: Teoría y Métodos en las Arqueologías de la Experiencia y la Corporeidad», dictado por el Dr. F. Acuto. Facultad de Filosofía y Letras, Universidad de Buenos Aires. Ms.

2008a Circulación e Interacción en el valle Calchaqui entre el siglo IX y la primera época de contacto con los españoles: Explorando la dinámica social tardía. Informe final presentado al CONICET. Ms.

2008b El mundo en movimiento. Circulación de materiales, información y personas en sociedades tardias del valle Calchaqui (Salta). Monografía final aprobada para el Curso de Posgrado «El rol del intercambio en las sociedades pre-estatales. Perspectivas antropológicas y arqueológicas», dictado por la Dra. M. A. Berón. Facultad de Ciencias Sociales, Universidad Nacional del Centro de la Provincia de Buenos Aires. Ms.

2008-09 «Alucinaciones en circulación. Una mirada a la interacción surandina tardía desde las tabletas y tubos de La Paya (valle Calchaquí, Salta)». Anales del Instituto de Arqueología y Etnología № 63-64: 81-105.

2010a El mundo en movimiento: circulación de bienes, recursos e ideas en el valle Calchaquí (Salta). Una visión desde La Paya. Tesis Doctoral inédita. Buenos Aires: Facultad de Filosofía y Letras, Universidad de Buenos Aires.

2010 b «La «Colección La Paya» un siglo después». Arqueología N 16: 237-251.

SPROVIERI, Marina y Lidia BALDINI

2007 «Aproximación a la producción lítica en sociedades tardías. El caso de Molinos I, valle Calchaquí central (Salta)». Intersecciones en Antropología 8: 135-147.

Sprovieri, Marina y Michael Glascock

2007 «Aproximación a la circulación de obsidiana en el valle Calchaquí salteño entre los siglos IX y XV», en Actas del XVI Congreso Nacional de Arqueología Argentina, Revista Pacarina $N^{o}$ Especial, Tomo 3, pp. 221-226. San Salvador de Jujuy: Universidad Nacional de Jujuy.

SPROVIERI, Marina y Stella M. RIVERA

2014 «Las maderas de la «Colección La Paya». Circulación y consumo en el valle Calchaquí (Salta)». Intersecciones en Antropología 15 (1): 89-102.

Stuiver, Minze, Paula J. Reimer y Ron W. ReImer

2005 Calib Radiocarbon Calibration Program. http://calib.qub.ac.uk/calib.

TARRAGÓ, Myriam

1970 «Panorama arqueológico del sector septentrional del valle Calchaquí. Salta», en Actas y Trabajos del $1^{\circ}$ Congreso Nacional de Arqueología Argentina, pp. 221233. Santa Fe.

1974 «Aspectos ecológicos y poblamiento prehispánico en el valle Calchaquí, provincia de Salta, Argentina». Revista del Instituto de Antropología $\mathrm{n}^{\circ} \mathrm{V}$ : 195-216.

1980 «Los asentamientos aldeanos tempranos en el sector septentrional del valle Cal- 
chaquí, Provincia de Salta, y el desarrollo agrícola posterior». Estudios de Arqueología 5: 29-53.

1984 «La historia de los pueblos circunpuneños en relación con el Altiplano y los Andes Meridionales». Estudios Atacameños 7: 116-132.

1996 «El Formativo en el Noroeste argentino y el alto valle Calchaquí», en Actas y Memorias del XI Congreso Nacional de Arqueología Argentina, $11^{\circ}$ parte, Revista del Museo de Historia de San Rafael 23 (1/4), pp. 103-119. Mendoza.

2000 «Chacras y pukara. Desarrollos sociales tardíos», en Nueva Historia Argentina. Los pueblos originarios y la conquista, M. Tarragó, dir., pp. 258-300. Buenos Aires: Editorial Sudamericana.

TARragó, Myriam y Mónica De Lorenzi

1976 «Arqueología del valle Calchaquí». Etnía 23-24:1-35.

TARragó, Myriam, María CARrara y Pío P. Díaz

1979 «Exploraciones arqueológicas en el sitio SSalCac 14 (Tero), Valle Calchaquí». Antiquitas 2: 231-242.

TARRAGó, Myriam y Luis GonZÁLEZ

2003 «Los Graneros: un caso de almacenaje incaico en el Noroeste Argentino». Runa 24: 123-149.

TARRAGó, Myriam, Luis GonZÁLEZ y Javier NASTRI

1997 «Las interacciones prehispánicas a través del estilo: el caso de la iconografía santamariana». Estudios Atacameños $\mathrm{N}^{\circ}$ 14: 223- 242.

TARTUSI, Marta y Víctor NúÑEZ RegueIRo

2003 «Procesos de interacción entre poblaciones de los valles intermontanos del NOA y las de piedemonte». Anales Nueva Epoca «Local, Regional, Global: prehistoria, protohistoria e historia en los Valles Calchaquies» 6: 43-62.

TORRes, Costantino M.

1998 «Psychoactive Substances in the Archaeology of Northern Chile and NW Argentina. A Comparative Review of the Evidence». Chungará 30 (1): 49-63.

URIBE, Mauricio

2002 «Sobre alfarería, cementerios, fases y procesos durante la prehistoria tardía del desierto de Atacama (800-1600 dC)». Estudios Atacameños 22: 7-31.

Valencia, Rafael F. J., Teodoro Chafatinos, Roberto A. Ibarguren, Rubén P. Menegatti y Adelqui OcARANZA

1970 Los suelos de los valles Calchaquies, Provincia de Salta (Primera parte. Estudio de campo). Gobierno de la Provincia de Salta - Universidad Nacional de La Plata.

VITRY, Christian

2008 El Nevado de Cachi. Córdoba: Palloni Ediciones.

WAGNER, Duncan L.

1932 La civilización chaco-santiagueña. Conferencia del Sr. Duncan L. Wagner pronunciada en el Centro Naval de Buenos Aires el 23 de abril de 1923. Buenos Aires: Cía. Imp. Argentina.

WiLliams, Verónica

1983 «Evidencia de actividad textil en el establecimiento incaico Potrero Chaquiago 
(Provincia de Catamarca)». Relaciones de la Sociedad Argentina de Antropología 15: 49-59. Buenos Aires.

2004 «Poder estatal y cultura material en el Kollasuyu». Boletín de Arqueología PUCP 8: 209-245.

Williams, Verónica, María P. Villegas, María S. Gheggi y María G. Chaparro

2005 «Hospitalidad e intercambio en los valles mesotermales del Noroeste argentino». Boletín de Arqueología de la PUCP 9: 335-373.

Williams, Verónica y Terence D’Altroy

1998 «El sur del Tawantinsuyu: un dominio selectivamente intensivo». Tawantinsuyu 5: 170-178.

Yacobaccio, Hugo, Patricia Escola, Fernando Pereyra, Marisa Lazzari y Michael GLASCOCK

2004 «Quest for Ancient Routes: Obsidian Sourcing Research in Northwestern Argentina». Journal of Archaeological Science 31: 193-204. 